\title{
Electrical load sizing methodology to aid conceptual and preliminary design of large commercial aircraft
}

\author{
Ravinka Seresinhe \\ (Department of Aerospace Engineering), Cranfield University, UK \\ Craig Lawson \\ (Department of Aerospace Engineering), Cranfield University, UK
}

\begin{abstract}
The importance of the more electric aircraft (MEA) has been highlighted in many publications, projects and industrial presentations. By definition the MEA concept achieves the majority of the required system functionality by using electrically powered sub-systems and components. This manifests itself in much higher electrical power demands on-board aircraft, compared to conventional architectures. This presents many challenges in the design process. To alleviate the risk and choose the optimum architectures for the systems on the aircraft, it is essential to incorporate the characteristics and possible configurations of the electrical network in the conceptual and preliminary design stages. Hence the current practice of performing an electrical load analysis at the detail design stage is not adequate. To address this gap, this paper presents a viable and robust methodology to define requirements, size components and systems, and calculate the electric power requirements at the preliminary design stages. The methodology uses the conventional aircraft, systems and components as the baseline and uses
\end{abstract}


mathematical techniques and logical sequences of component operation, developed through the research, to size electrical loads profiles for conventional aircraft. It then adapts this result to the MEA concept by adding key components which would account for the difference between a conventional system and a more electric system. The methodology presented here makes the design process more robust and aides the choice of the optimum design for the aircraft.

\section{Keywords}

Aircraft design, aircraft systems, electrical load analysis, more electric aircraft

\section{Nomenclature}

Abbreviations

AC

ACARE

APU

ASTM

ATA

CAA

$\mathrm{CO}_{2}$

ECS

EHA

ELA

EMA

IPS
Alternating Current

Advisory Council for Aeronautics Research in Europe

Auxiliary Power Unit

American Society for Testing and Materials

Air Transport Association

Civil Aviation Authority (UK)

Carbon Dioxide

Environmental Control System

Electro Hydrostatic Actuator

Electrical Load Analysis

Electro Mechanical Actuator

Ice Protection System 
MEA

MTOW

NASA

NOx

PAX

VHF

List of Symbols

A

ALin

$A L$ in_cabin volume

ALin_pilots

$\mathrm{CL}$

Cont.

CR

DC

DE

GR

ID

IDCabin_Lamps

IDN

IDNO

IDP

IDVHF
More Electric Aircraft

Maximum Take-Off Weight

National Aeronautics and Space Administration (USA)

Nitrous Oxides

Number of Passengers

Very High Frequency

Wall area of the cabin

Aircraft level inputs

Aircraft level input - Cabin Volume

Aircraft level input - Number of Pilots

Climb phase

Continuous loads

Cruise phase

Direct current

Descent phase

Ground phase

Component identification parameters

Cabin lamps identification parameters

Designated component name

Number of components of the same designation

Accumulated nominal power of components with the same designation

VHF equipment identification parameters 


\begin{tabular}{|c|c|}
\hline Int. & Intermittent loads \\
\hline LA & Landing phase \\
\hline LO & Loiter phase \\
\hline$L_{p}$ & Load priority \\
\hline $\mathrm{m}$ & Mass flow rate of air \\
\hline$N_{A C}$ & Number of avionics compartments \\
\hline $\mathrm{N}_{\mathrm{APU}}$ & Number of auxiliary power units \\
\hline $\mathrm{N}_{\mathrm{BF}}$ & Number of Blowers in the avionics compartments \\
\hline $\mathrm{N}_{c C}$ & Number of cabin compartments \\
\hline $\mathrm{N}_{\mathrm{CP}}$ & Number of conditioning packs in the ECS \\
\hline $\mathrm{Ne}$ & Number of engines \\
\hline Nopr & Number of components operating simultaneously \\
\hline $\mathrm{NPC}$ & Number of pressure controllers \\
\hline NRAM & Number of ram air inlets \\
\hline $\mathrm{N}_{\mathrm{RF}}$ & Number of re-circulation fans \\
\hline $\mathrm{Nzc}$ & Number of zone controllers \\
\hline $\mathrm{Pe}$ & Ratio between the ambient and cabin pressures \\
\hline $\mathrm{P}_{\mathrm{ECS}+\text { Pneu }}$ & $\begin{array}{l}\text { Combined electrical power for the pneumatic system and the } \\
\text { environmental control system }\end{array}$ \\
\hline $\mathrm{P}_{\mathrm{NCR}}$ & Power of a designated component in the cruise phase \\
\hline$P_{\text {net_EECS }}$ & Net power for an electric ECS \\
\hline SLin & System level inputs \\
\hline$T^{\prime}$ e & Ratio between the ambient and cabin temperatures \\
\hline $\mathrm{T}_{\mathrm{c}}$ & Cabin temperature \\
\hline
\end{tabular}


$\mathrm{T}-\mathrm{O}$

Topr

$U$

Vopr

Y

$\varepsilon$

$\varphi$
Take-Off phase

Time of operation

Thermal conductivity of the cabin skin

Nominal operational Voltage

Ratio of the specific heat of air

Efficiency of the heat exchanger

Ratio between the ambient and aft compressor temperatures 


\section{Introduction}

The expected annual growth rate of $4.7-4.8 \%$ over the next 20 years in air travel (in terms of revenue passenger kilometres) [1] means that in the future, aviation may have a greater negative environmental impact. The challenge will be to have more aircraft operating more of the time yet have a lesser adverse environmental impact overall compared to the present. To realise this challenge, in Europe, ACARE has set out certain goals which are to be achieved by 2020 . Among these, a $50 \%$ reduction of the perceived noise compared to average noise levels in year 2000 , a $50 \%$ cut in $\mathrm{CO}_{2}$ emissions per passenger kilometre and an $80 \%$ cut in $\mathrm{NO}_{x}$ emissions compared to year 2000 are vital [2]. All these goals directly affect not only how an aircraft is operated but also how an aircraft is designed and built.

The conventional large commercial aircraft which includes almost all aircraft with the exception of the Boeing 787 series has three main types of power sources to run the systems on-board. Since this power is not directly related to providing thrust for movement, it is commonly referred to, as secondary power. Systems on-board the aircraft such as the environmental control system (ECS), ice protection system (IPS) as well as some other minor systems are run by pneumatic power. Systems such as the primary and secondary flight control surface actuation and, landing gear actuation are powered by the aircraft hydraulic system. Systems such as the communication and navigation system, the lighting, the galley, and the in-flight entertainment are operated by the electrical network.

In recent times, with the rising fuel costs and the emphasis on more environmentally friendly aircraft technologies, major focus has been placed on designing and 
producing more electric aircraft. For the purpose of this research the "more electric aircraft" has been defined as an aircraft which uses proportionally more electrical secondary power than a legacy or conventional aircraft. An "all-electric aircraft" can be defined as an aircraft that uses only electrical secondary power, by dispensing with hydraulic and pneumatic power.. Feiner [3] suggests that aircraft with all electric secondary power systems are expected to "cost less, be more reliable and be less expensive to operate". He also goes on to say that benefits include reduced design complexity, reduced parts count, easier aircraft modification and less environmental impact. It is further endorsed by Arguelles et al in [2], where the MEA is highlighted as a pathway to achieving a lower environmental impact due to aviation. Moreover, it means that future aircraft will possibly have most equipment operating through electrical power.

The basis for this paper relies on some key aspects. Firstly it should be realised that the current practices in estimating the electrical load at the preliminary design stage are not adequate. Furthermore it should also be understood why there is a necessity to incorporate electrical load considerations at the preliminary design stage.

\subsection{Current practice for electrical load sizing}

The aircraft conceptual design and preliminary design procedures are well documented in a number of publications including [4], [5], [6], and [7]. There is a large volume of literature describing the development of electrical components for conventional and future aircraft as well. Roskam [4] as well as airframe manufacturers [8], [9] provide aircraft level electrical load profiles, but a numerical sizing method based on historical data or otherwise, is not provided. CAA (UK) [10] 
provides the guidelines on how to perform an analysis and is aimed at the detailed design phase.

By using conceptual sizing methods which rely on statistical fitting, an approximation of the total engine mounted generator rating may be obtained. The "Tot Elec" curve in Figure 1 represents the published engine mounted generator capacity [11] . It was found that these results, which were predicted using conceptual sizing techniques, showed significant deviations from the published data.. More importantly, the total generator rating alone is not adequate for further design and analysis at a preliminary design stage and a more robust systematic prediction of required power levels is needed.

. The $f(M T O W)$ represents the generator capacity calculated as a function of the MTOW. The $f(P A X)$ represents the generator capacity calculated as a function of the number of passengers in the maximum density configuration. The $f(M T O W, P A X)$ is when the MTOW and the PAX are both used as variables. To keep the data consistent during the statistical fitting, PAX and MTOW variables are for the maximum passenger density configuration for each aircraft type. 


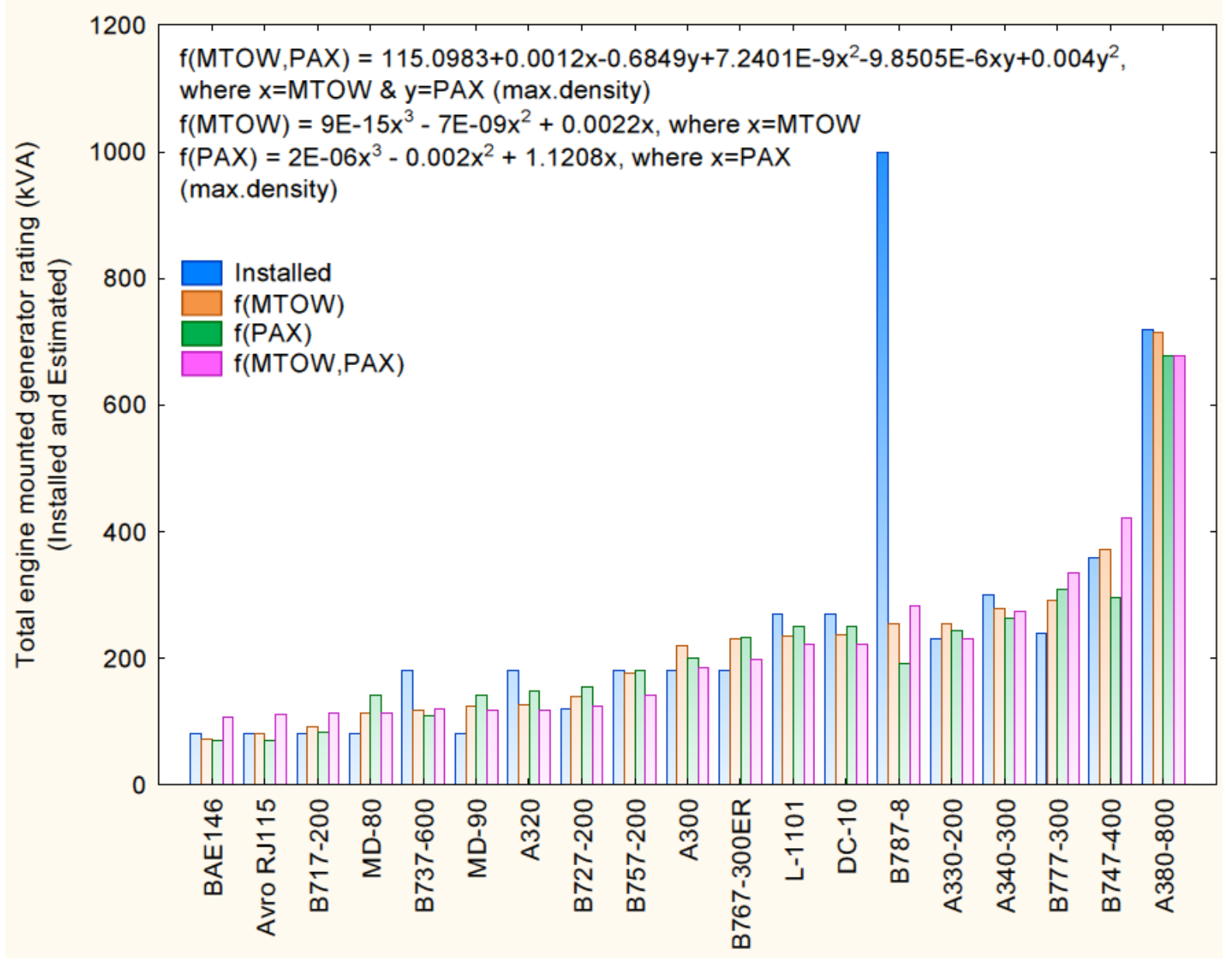

Figure 1: Estimated vs published total engine mounted generator ratings

The aircraft electrical system requirements are heavily dependent on all other aircraft systems. The consumer components of the electrical system are solely dependent on other aircraft systems. The generation and distribution architecture is decided upon the technology level and power consumption of the components required for the systems. This process can only be done at a detail design stage since only at this stage will all components be fully defined. Hence the understanding of the capacity of the electrical system at the preliminary design stage is limited to a prediction achieved using empirical methods which rely on conceptual sizing methodologies and previous experience. This limits the ability to provide more 
efficient tailor-made solutions for each type of aircraft. It was observed that throughout the range of aircraft studied in this research, the installed generator capacity was at times much higher than expected for the mass and passenger count of the aircraft. MEA will most likely have varying electrical loads among different aircraft types. To maintain the efficiency of $M E A$, , it is important to have prediction tools which will enable designers to provide tailor-made solutions which are not oversized..

The ASTM F2490-05e1 (standard guide for aircraft electrical load and power source capacity analysis) sets the standard for the aircraft electrical system sizing. Yet this is only achievable through a full aircraft electric load analysis and can only be conducted once all the electrical components of the aircraft are decided upon. Hence it can only be completed after the detail design phase of an aircraft. An example is given by the Civil Aviation Authority (CAA) UK in [10] and it can be seen that each component needs to be listed and then a full analysis carried out. The procedure is quite straightforward, and the total power is summed up in each flight phase according to which electrical components would be needed to operate in a given flight phase. However, the procedure relies heavily on manufacturer data. Due to the sheer number of different manufacturers for various components, only the airframe manufacturer could calculate the electrical loads accurately due to the lack of availability of data. Moreover, this could only be done once all the electrical equipment was established. 


\subsection{Conventional electrical power demands}

The conventional large aircraft has systems run purely on electricity as well as systems which require electrical power but use pneumatic or hydraulic power as the main type of power. Hence to get a better understanding of what components are run by which type of power, it is worthwhile to discuss certain systems briefly.

Environmental Control System (ECS) - The ECS carries out the essential functions of ventilation and pressurisation as well as thermal regulation. Typically in the conventional aircraft the ECS is powered mainly by the bleed air extracted from the engines hence it is pneumatically powered. However certain equipment necessary to maintain the functionality of the ECS are powered electrically. The re-circulation fans, many pressure regulating valves, the monitoring and controlling computers, and a variety of controllers are run electrically.

Ice Protection System (IPS) - The IPS is in charge of providing ice and rain protection. One of the primary concerns for the IPS is the build-up of ice on the wing and the majority of the energy required by the IPS is to carry out wing anti-icing. In the conventional large aircraft, the wing anti-icing is typically done using hot bleed air extracted from the engines. Hence the main power is in pneumatic form. However, for the anti-icing of probes, the wipers, the ice detectors, the anti-icing and demisting of cockpit windows, and the operation of some valves and most controllers, electrical power is used.

Hydraulic System - The hydraulic system in conventional large aircraft is tasked with the actuation of flight control surfaces. Most components in the system are powered by engine driven pumps pressurising the hydraulic fluid for transmission. Controllers 
and measurement valves in the system are powered electrically. Typically, hydraulic reservoirs are pressurised using engine bleed, thus introducing a pneumatic power component as well.

Fuel system - It is typical to have electrically powered pumps for engine feed in fuel systems of large conventional aircraft. But it is also common to have jet pumps (which uses fuel as the working fluid) to carry out less critical tasks, such as transfers to the outer tanks. The monitoring and measuring systems are also typically powered by electrical power.

Other systems - Systems such as the lights, navigation, communication, auto pilot, flight control system, indicating and recording, and water and waste systems are typically powered by electricity.

A comprehensive description of airframe systems and airframe system architectures are given in [12].

A typical conventional secondary power breakdown is shown below in Figure 2.

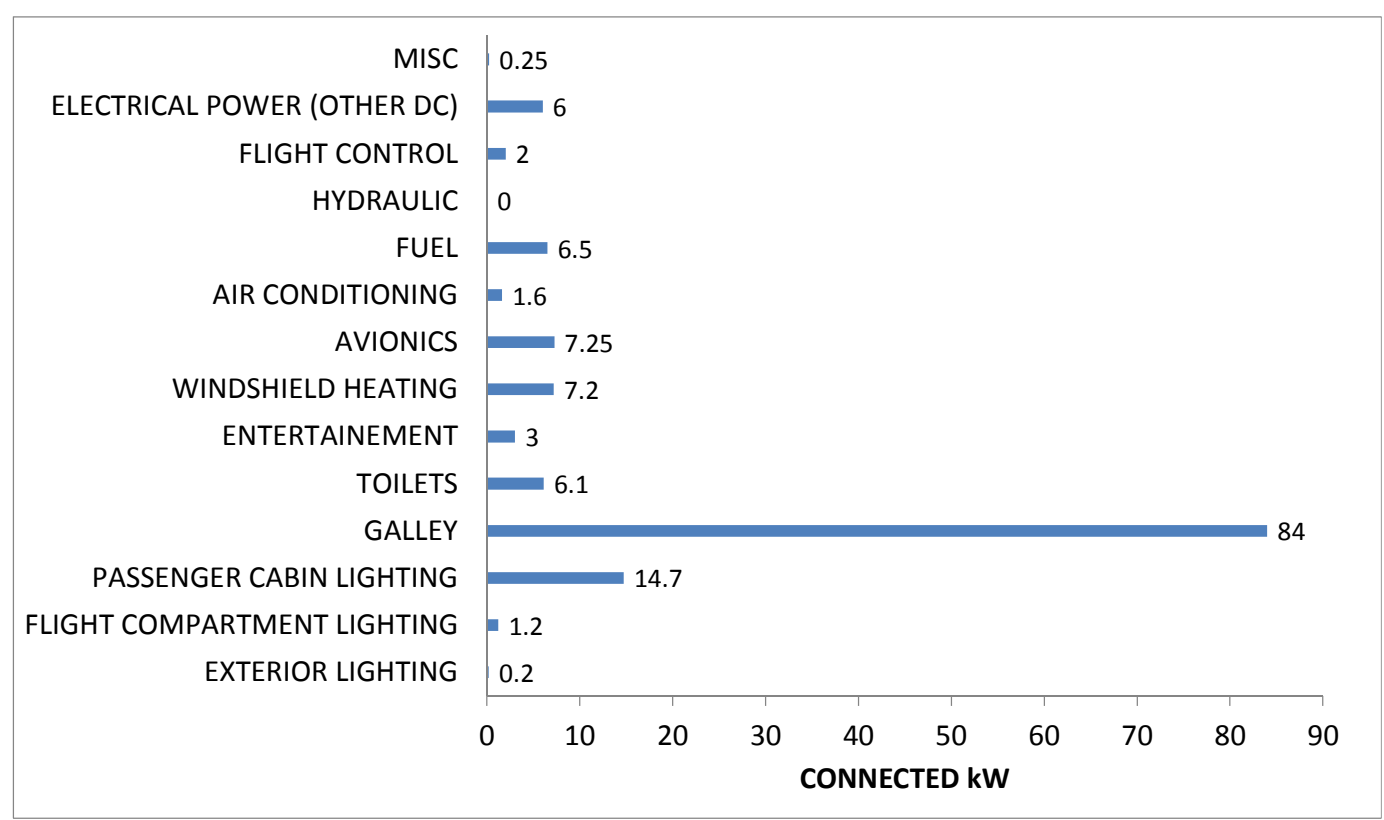


Figure 2: DC-10 power demands at a typical cruise [4]

\subsection{More electric secondary power demand}

Two separate studies done by airframe manufacturers and research centres such as the National Aeronautics and Space Administration (NASA) give an indication of what loads would be present in a typical all electric secondary power system for civil passenger aircraft.

The following illustration shows the estimated loads for 300 passenger tri-engine aircraft. [13] These are a result of studies conducted by the NASA Lewis Research Centre to assess the operational, weight and cost advantages for commercial transport aircraft with all-electric secondary power systems.

The following is an illustration on the load results found in the studies.

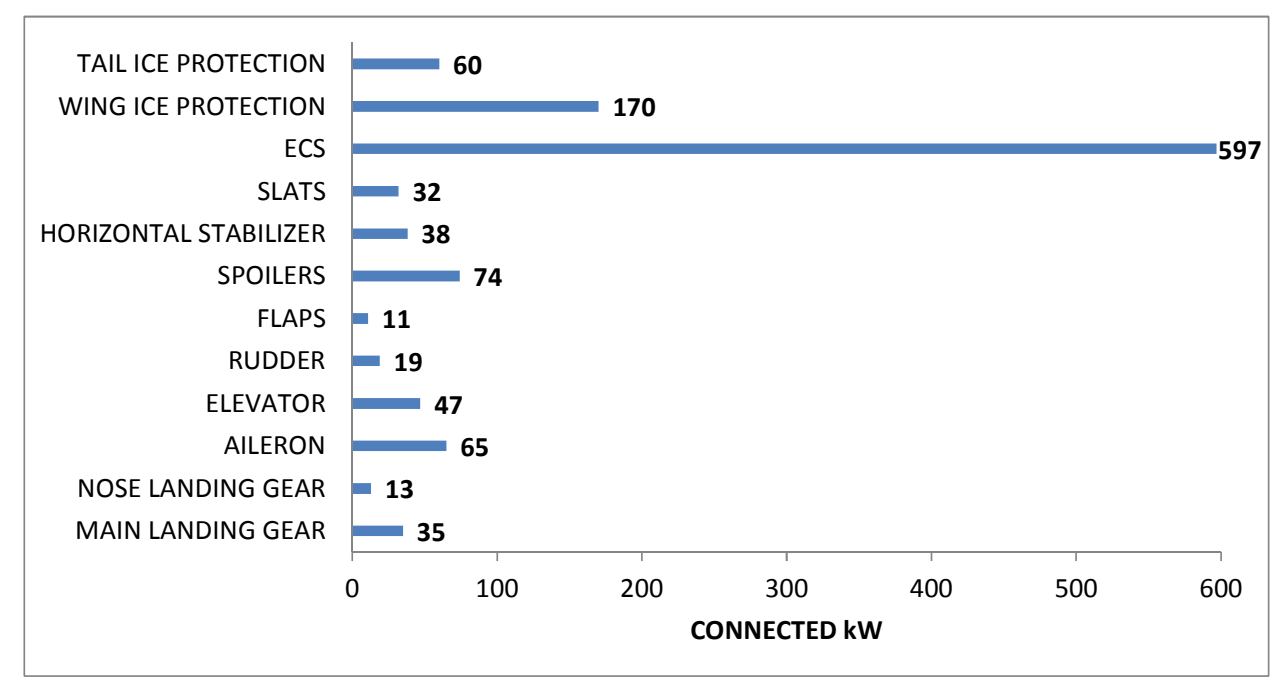

Figure 3: Electric load demands - 300 passenger, tri engine aircraft [13]

A further separate study by NASA on a 600 passenger, 4 engine aircraft produced the following preliminary estimates. 


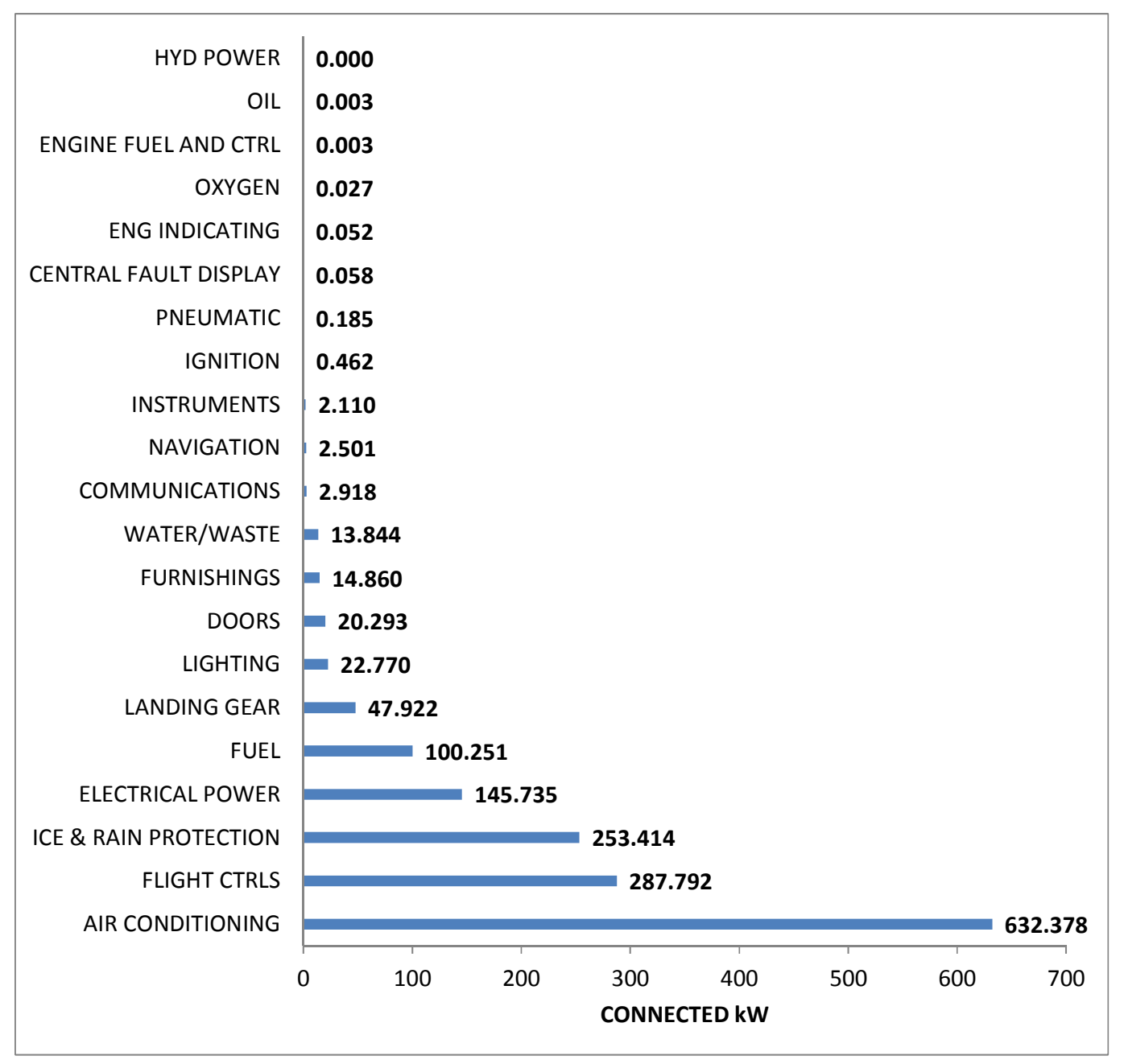

Figure 4: Electric load demands - 600 passenger, four engine aircraft [3]

The two studies, though focusing on MEA, were done for different aircraft sizes. The loading details of the studies cannot be directly compared due to the differences in the breakdown of loads. However, there are certain observations which are common in both cases. The ECS is established as the largest power user by a considerable margin. Other major power users are the, IPS and the flight control actuators, all three of these loads are not powered electrically in the conventional configurations. More data on MEA sizing is needed to form empirical relations for systems sizing. However, more importantly accurate prediction tools are required to prevent oversizing of the electrical system. 


\subsection{Motivation for study}

From comparing with a 300 seat conventional aircraft from Figure 1 (eg.-B767) to Figure 3 , it is interesting to note that the all-electric configuration requires more than four times the electrical power that is needed on the conventional configuration.

With the increasing electrical load in future aircraft, more demand is naturally placed on analysing and preparing for design challenges, in the preliminary design stages of the electrical network.

Moreover, by analysing the results in Figure 1 it is clear that in choosing the generator ratings other factors such as development costs and availability of off-theshelf products have played their parts.

The deviation seen in Figure 1 for the Boeing 787-8 and the evidence in Figure 3 and Figure 4 indicates that with the development of more electric technologies, the electrical load requirements of aircraft vary widely even within the same size range. One of the reasons for this variation is due to the choice of design for the subsystems. The electric loads will be dependent on which sub-systems are migrated from pneumatic, hydraulic or mechanical power usage to electrical power usage. Moreover, the level of technology of the components of each electric sub-system will also affect the electrical loading requirements of the aircraft. Hence using off-theshelf generators will be an extremely inefficient option which will significantly impact the aircraft and systems performance with the possible risk of oversizing of the generators and distribution network. 
This presents the case for designing electrical generators according to the specificities of an aircraft. In order to achieve this efficiently the design process needs to be addressed as early as possible in the aircraft design stage.

This is further endorsed by Feiner [3] who says that the "power capacity must be estimated early in the aircraft's design cycle in order to support engine development". Hence to achieve this efficiency, a robust and adaptive electrical load sizing and analysis tool is needed, which can incorporate uncertainties such as future component loads and also adapt to changes in the design requirements through the aircraft development cycle.

Moreover, it also facilitates the initial steps in relating aircraft level objectives to system level choices, the importance of which is extensively discussed in [14]. Also with novel concepts in operation and optimisation of aircraft operation, the effects of systems need to be considered with great care [15]. To facilitate this, methodologies need to be in place at the early design stage to calculate the power requirements of the airframe systems to a reasonable level of accuracy and detail.

In summary, the following methodology for electrical load sizing tries to overcome the limitations of empirical methodologies currently used at the preliminary design stage. This is achieved by using a generic baseline electrical load architecture which, can be adapted and modified to any aircraft, conventional or more electric. The method bridges the gap between a predicted generator load based on conceptual sizing methods, and the precise electrical load analysis which can be done at the detail design stage. 


\section{Methodology - electrical load sizing \& analysis tool}

Esdras and Liscouet-Hanke [16] presents a methodology developed at Bombardier which relies on predicting the electrical loads at a systems level by studying the trends in the power consumption of past and present aircraft. Since the more electric concept is relatively new, a more robust methodology where the component loads are considered needs to be adapted. This enables the methodology to then be adapted to a more electric design, simply by adding characteristics of electrical components, needed to design more electrical airframe systems architectures.

The following illustration shows the architecture on which the developed model is based on. 


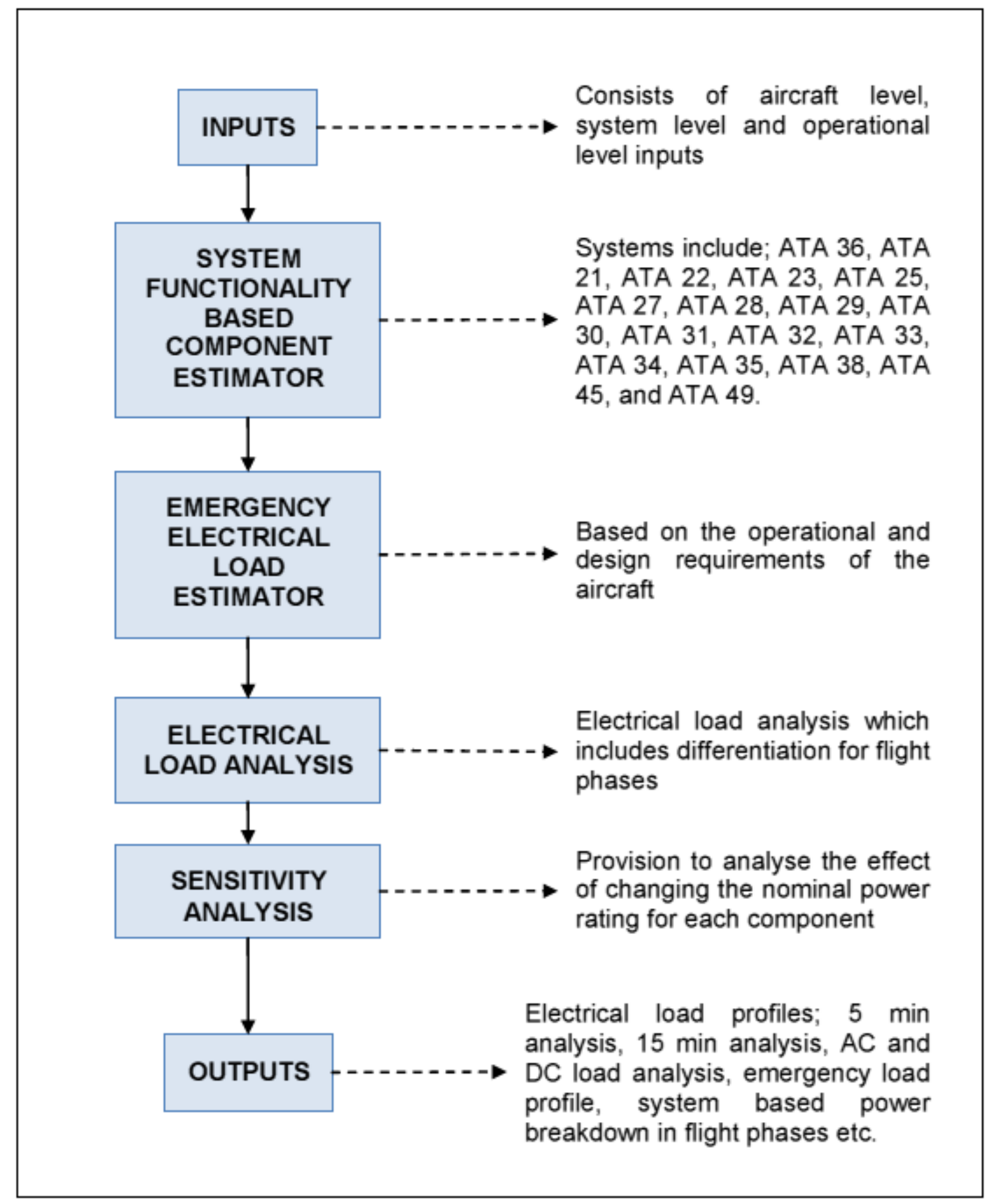

Figure 5: Architecture of electrical load analysis tool

The development of this tool was carried out with the intention of aiding the preliminary design process of an aircraft. The tool is designed such that it can be 
adapted to a conventional configuration or an all-electric configuration. The baseline configuration is the conventional system. To achieve the all-electric configuration, all systems components which are powered non-electrically can be easily replaced by electrically powered equivalent equipment within the tool itself. The model has been implemented by using Microsoft Excel and the Visual Basic programming language.

The inputs for the model are classified under three categories. Firstly, there are the aircraft level inputs. These inputs are used to size the basic configuration of the each system. Furthermore, it has system level inputs which relate to various system functionalities and operational level inputs. These inputs are used to allocate the minimum equipment lists to each of the sub-systems. The operational level inputs are restricted to only include provision for simultaneous operation of the same equipment. The operational inputs cannot be used to simulate a potential flight where certain components may be switched on or off at random, since the purpose of this tool is to aid the design process in which the highest loading scenarios are analysed. The list of inputs is shown in Appendix 1.

The system based component estimator receives information from the inputs and estimates the minimum number of components needed to achieve the required level of system functionality. Characteristics of functionality related to each different system are used as constraints in the component estimator. This ensures that regardless of the aircraft level inputs, the minimum required system functionality is achieved each time in each system.

The main task of the emergency load estimator is to define which electrical equipment in each system is essential to the aircraft. "Essential" in this context is 
defined as the minimum equipment list needed to maintain safe flight. By having predefined functions that are essential to safe flight, the emergency load estimator assigns a tag to each component; assigning it as essential or non-essential defining that particular electrical component to be flight critical or not. The logic for the emergency load estimator was derived by studying the electrical bus equipment lists and the essential bus equipment for the Airbus A320 and the Airbus A430 series. It also calculates the loads on the essential buses of the aircraft and is herewith referred to as the emergency load. The logic is limited to the conventional architecture. Hence for more electric aircraft studies, each new component needs to be defined either essential or non-essential according to the design requirements of the aircraft.

The electrical load analysis is the core module of the tool. This extracts all the information from the component estimator and the emergency load estimator and lists all equipment and related data. It then couples the data with the "operational matrix", which enables it to calculate the electrical load profile.

The operational matrix contains vital information needed to perform the electrical load analysis.

Table 1: Format of component related information for electrical load analysis (ELA)

\begin{tabular}{|ccc|cccccc|cc|c|}
\hline ID & Topr & Vopr & Nopr & GR & T-O & CL & CR & DE & LO & LA & Lp \\
\hline A1 & C & $115 \mathrm{VAC}$ & 1 & 0 & 0 & 1 & 1 & 1 & 0 & 0 & $n$ \\
\hline
\end{tabular}


ID - Component ID (Includes component name, number of components, nominal power usage)

$T_{o p r}$ - Defines the operation time (Continuous or Intermittent)

Intermittent loads are defined as loads occurring for duration of 5 minutes or less whereas continuous loads will operate for duration of 15 minutes or more.

$V_{\text {opr }}$ - Nominal operational voltage

$N_{o p r}$ - Number of components operating simultaneously

GR - "Ground" phase

T-O - "Take-Off" phase

$\mathrm{CL}$ - "Climb" phase

CR - "Cruise" phase

DE - "Descent" phase

LO - "Loiter" phase

LA - "Landing" phase

$L_{p}$ - Defines the priority of the load (On an essential, shed or normal bus)

Since the intention of the sizing tool is to size the electrical system with design constraints (design for worst case scenario), the duration of the flight phase is not taken into consideration here. It is simply a case of where a load qualifies or has the possibility as being classed operational in each flight phase. A separate model is to be developed to analyse the load in flight operation which incorporates constraints related to time such as instances or operation and duration of operation and well as constraints related to power usage (\% of the nominal power usage for equipment with variable power consumption). 
For example for an AC load to be registered as a continuous load in "cruise" phase on a 115 VAC normal bus;

$$
\begin{gathered}
P_{N C R}=I D\left[I D_{N}=\text { "name", }\left(I D_{N O} \geq 1\right) \cap\left(I D_{P}>0\right)\right] \cap\left(T_{o p r}=\text { "c" }\right) \cap\left(V_{o p r}=" 115\right. \\
\text { VAC" }) \cap\left(N_{o p r} \geq 1\right) \cap(C R=1) \cap\left(L_{p}=" \mathrm{n} "\right)
\end{gathered}
$$

Where;

$P_{N C R}$ is the condition for active power for a named component under the "cruise" flight segment to be registered

$I D_{N}$ is the unique name assigned to the component

$I D_{N O}$ is the number of components of the same name

$I D_{P}$ is the accumulated nominal power of components of the same name

$$
I D_{N}=f\left(A L_{\text {in }}, S L_{\text {in }}\right)
$$

Where;

$A L_{\text {in }}$ are the aircraft level inputs

$S L_{\text {in }}$ are the system level inputs

A relation for each component needs to be constructed by looking at what affects the quantity of components at system and aircraft level.

For example, the quantity of Very High Frequency (VHF) radios needed for communication is directly related to the number of pilots so,

$$
I D_{V H F}=f\left(A L_{\text {in_pilots }}\right)
$$


For the estimation of the number of cabin lamps required to maintain the required luminosity of the cabin the cabin volume and the type of lighting also affect the result. Thus a combination of aircraft level and system level inputs affects the result.

$$
I D_{\text {Cabin_Lamps }}=f\left(A L_{\text {in_cabin volume, }} S L_{\text {in_Lighting type }}\right)
$$

The load priority is based on the system architectures of typical regional, short range and long range aircraft. The loads are categorised as essential or non-essential. Essential loads shall operate without disruption in the case of an emergency, thus are given a much higher priority over the other loads. These would typically operate under "essential" buses. All other loads are classed as "non-essential" and are not critical to maintain safe flight. Allocations are also made for loads that can be shedded.

The $I D_{P}$ is derived from a database within the tool. The database contains equipment data such as the nominal power usage and the mass, of electrical components used in aircraft.

The tool estimates the loads on a conventional electrical system. It is also imperative that the more electric aircraft, which was the motivation of the study, be analysed as well.

This tool can be combined with an electrical ECS, electro thermal IPS, Electro-Hydro static Actuators (EHA) or Electro-Mechanical Actuators (EMA) and any other more electric subsystems to analyse the electrical loading of an MEA.

The results of the tool are presented as a set of graphs and data values for ease of use. The tool gives overall loading values per flight segment, categorised by the 
voltage Bus type (AC, DC, AC SHED, DC SHED, AC ESS or DC ESS), by system designation (ATA chapter number), priority level (essential or non-essential) and operational time (continuous or intermittent).

\section{Validation}

Due to the lack of data, the generated electrical load profiles cannot be validated by direct comparison. Hence a separate validation strategy has been developed.

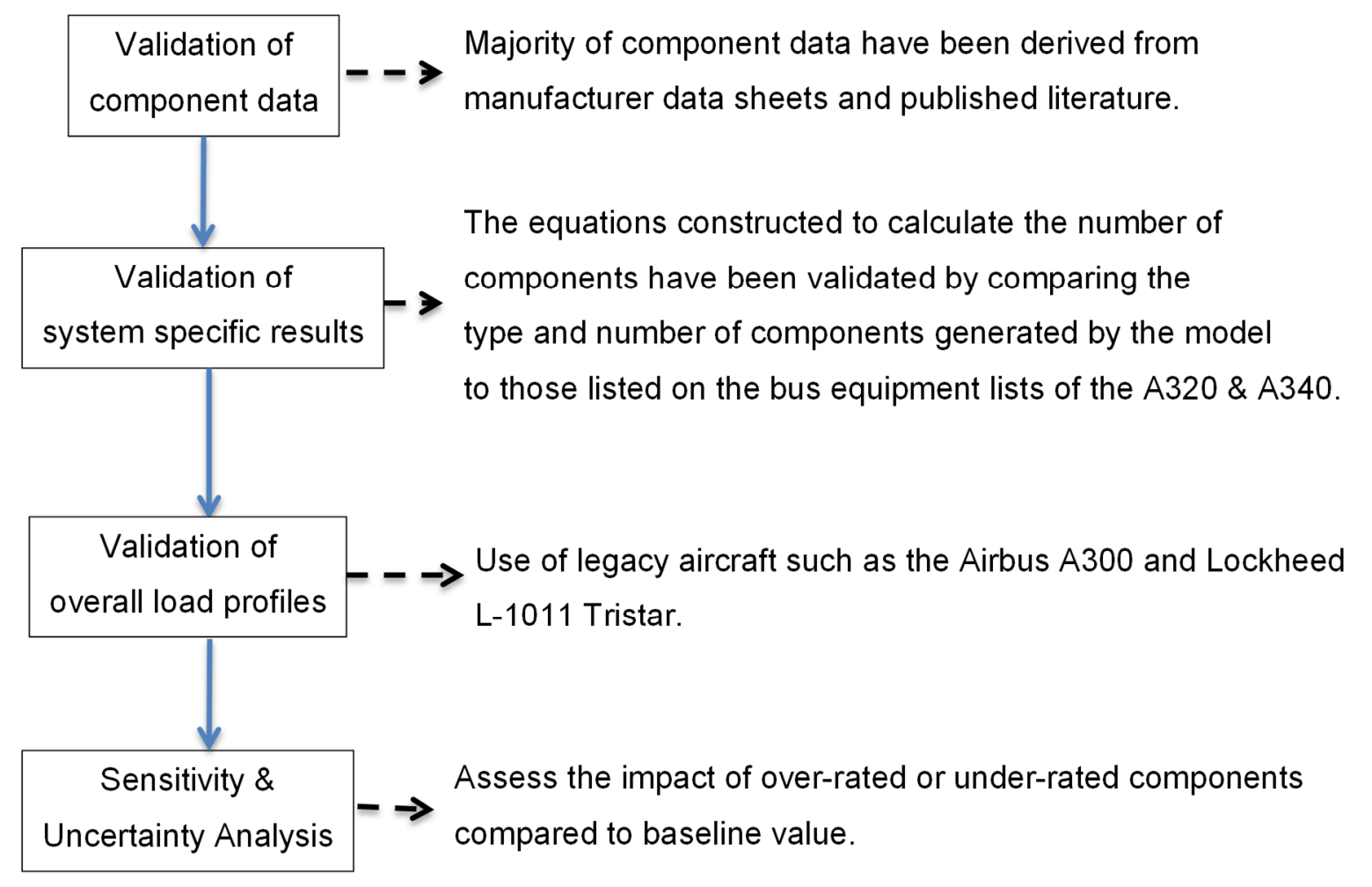

Figure 6: Validation strategy

Due to the complexity and demands of the aircraft secondary power system, each individual sub-system needed to be analysed and included in the design process of the tool, in order to achieve a satisfactory level of robustness. The system level 
power was the accumulated power of the components which were required to achieve the functionality of that particular system. This meant that at each of the calculation steps; component level, system level and aircraft level, there was the possibility of errors, and errors at the component level could be amplified at the aircraft level. To avoid such a scenario, a bottom-up validation strategy where component data, systems level results and aircraft level results were checked against published data, was needed. The validation strategy was based on the above requirement.

The choice of aircraft used in the validation procedure was based on the availability of data.

\subsection{Validation of component data}

Data sheets for components include(but not limited to) the following manufacturers; Eaton Aerospace, Ebm-papst, Aerospace Controls Corporation, GE Measurement \& Control Solutions, Parker (Aerospace), South Bend Controls, Goodrich (Aerospace), Dynon Avionics, Hartzell Aerospace, International Water-Guard Industries Inc, Adahan Carmeli Engineeing Co., Thales, Sarasota Avionics, Teledyne Controls, L-3 Communications, Columbia Research Laboratories Inc., Honeywell, Rockwell Collins, United Instruments Inc., Gables Engineering, Northrop Grumman Corporation, Avtech Tyee, Allied Signal (now Honeywell), Sermat Aero, B/E Aerospace, Aerolux, Astronics Corporations, Flight Display Systems, Pacific Precision Products and SensorsONE. 


\subsection{Publications include [17], [18] and [19].Validation at systems level}

In order to perform electrical load analysis at an aircraft level accurately, the inputs from the systems need to be within satisfactory ranges. To test the performance of the tool at a systems level, the tool was simulated to represent the Boeing 777-300. [20] lists the electrical loads for an "engine out" scenario (with a single main generator operating) in the cruise segment.

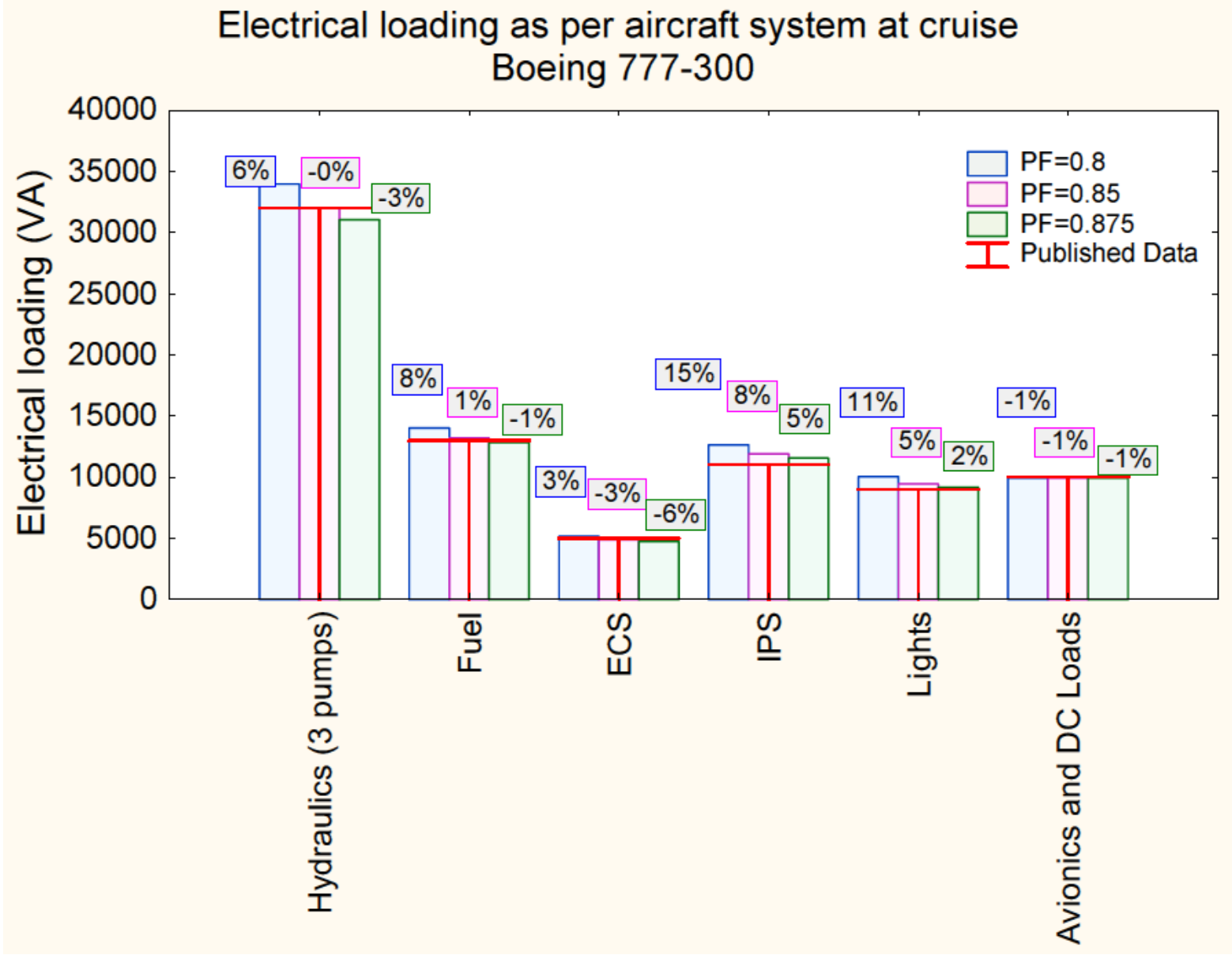

Figure 7: Electrical load at cruise (engine out scenario)

The tool computes the electrical load as a real power in kilo Watts. For comparison with the available data, a subset of typical power factors were used to convert the AC power component to an apparent power in volt amperes. The results showed that 
with a typical power factor of 0.85 the deviation was less than $10 \%$. Even with a conservative power factor of 0.8 , for an advance distribution such as the Boeing 777 architecture, the deviation was less than $15 \%$, clearly indicating that the model calculates the systems level power requirements satisfactorily. The validity is further increased since six aircraft systems, which are characteristically different, were compared.

It must be noted that the above sub-systems in Figure 7 were assumed to be fully operational and not compromised due to the engine out scenario. This is a valid assumption as all sub-systems listed are required to function to the respective minimum requirement to maintain safe flight. Engine out scenarios will result in power down sequences where non-essential systems such as in-flight entertainment and galley services are some of the first loads that would be shed.

\subsection{Validation at an aircraft level through comparison of electrical load profiles}

Airbus A300. When the Airbus A300 electrical load was simulated the following results were obtained. Airbus [8] provides data for the A300 electrical load analysis. The flight scenario used in the simulations for validation, is the "cold night cruise" where the worst possible conditions are assumed such that all electrical equipment may be used at least once. 


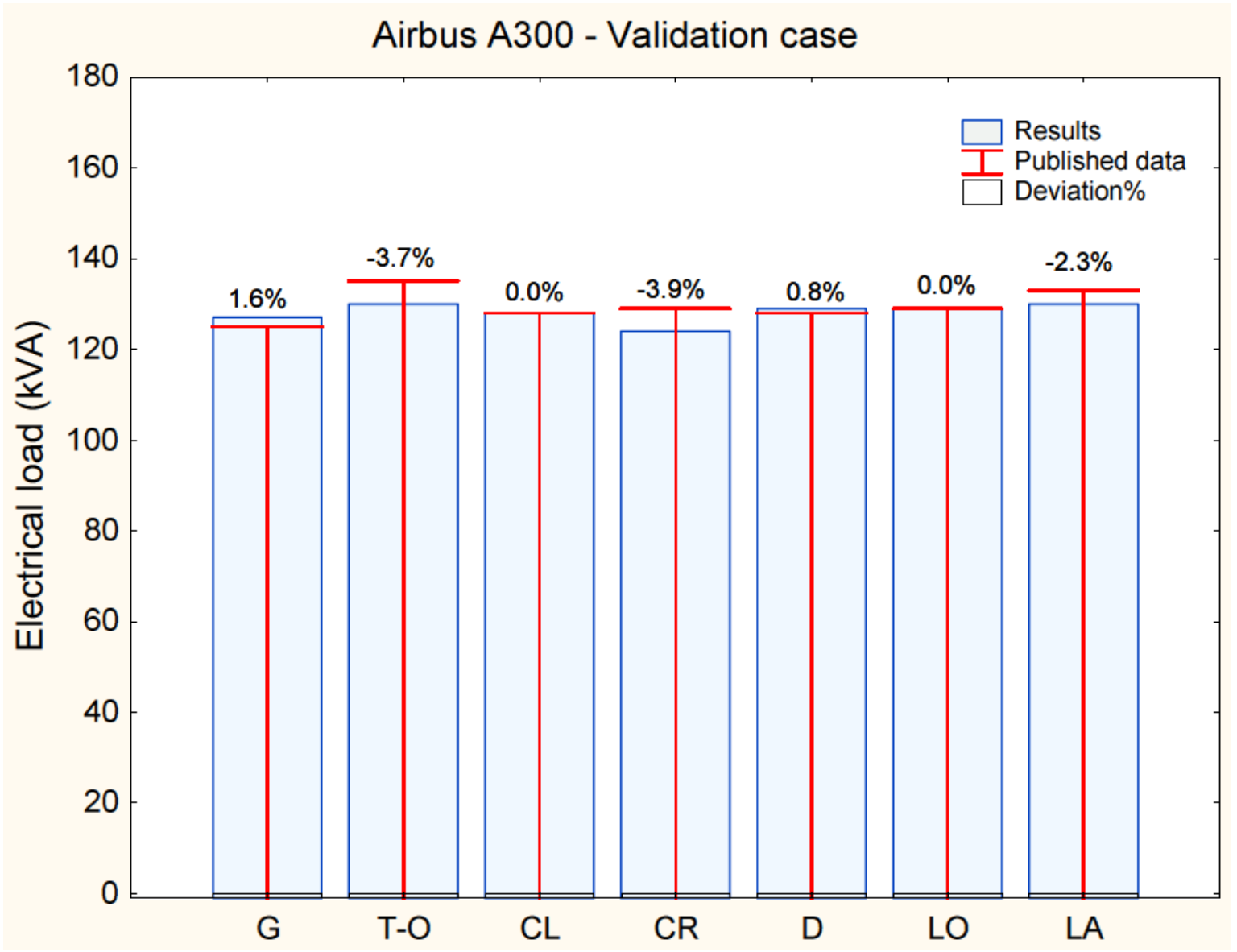

Figure 8: Airbus A300 study

As can be seen an accuracy of more than $95 \%$ was achieved in all flight segments. It should be noted that the scenario simulated was a "cold night cruise" in which all electrical equipment operated at least in one flight segment. The power factor used was 0.8 .

Lockheed L-1011 Tristar. The same process as for the Airbus A300 was repeated for the Lockheed Tristar, to observe the robustness and accuracy of the methodology and development tool, for aircraft from different manufacturers incorporating different design philosophies. [9] provides the data for the electrical load analysis of the L1011 Tristar. The flight scenario used was a "cold night cruise". 


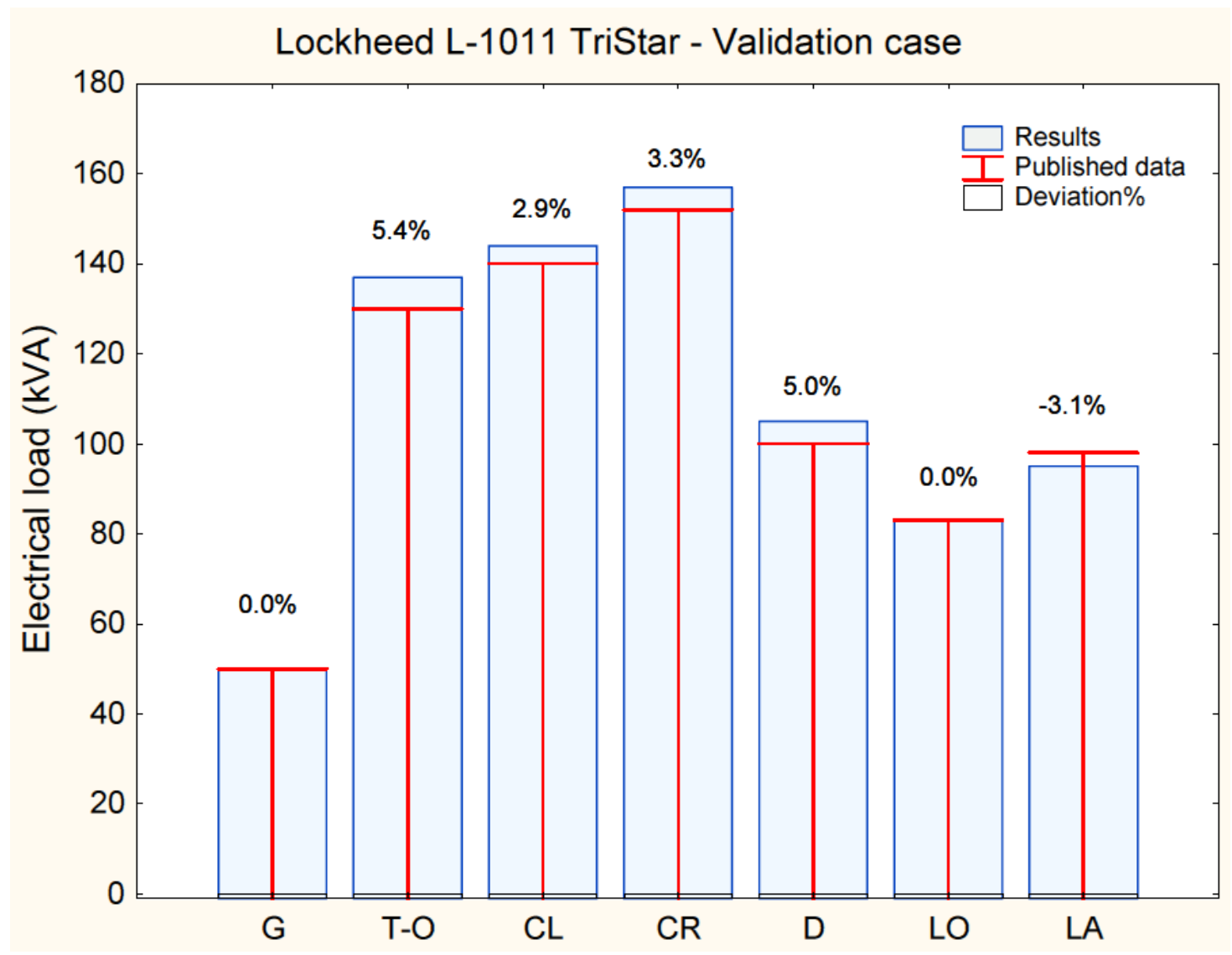

Figure 9: Lockheed L-1011 Tristar study [9]

As in the case of the Airbus A300, an accuracy of at least $90 \%$ was achieved within all flight segments. Each electrical component was operational for at least one of the flight segments. The power factor used was 0.8 .

\subsection{Sensitivity and un-certainty analysis}

The work presented in this paper relies on a key assumption; -

"The power-to-weight ratios of functionally similar electrical components are similar if not the same, in conventional commercial large aircraft."

Many aircraft use commercial off-the shelf products to fulfil many functionalities. By analysing available data on lighting components, fuel pumps, galley equipment, 
sensors, avionics equipment, in-flight entertainment equipment and many others, the above assumption can be justified.

To illustrate this, the electrically operated fuel booster pump characteristics were studied for the Airbus A330 [21], Airbus A430 [21] and Boeing 747 [22] series aircraft.

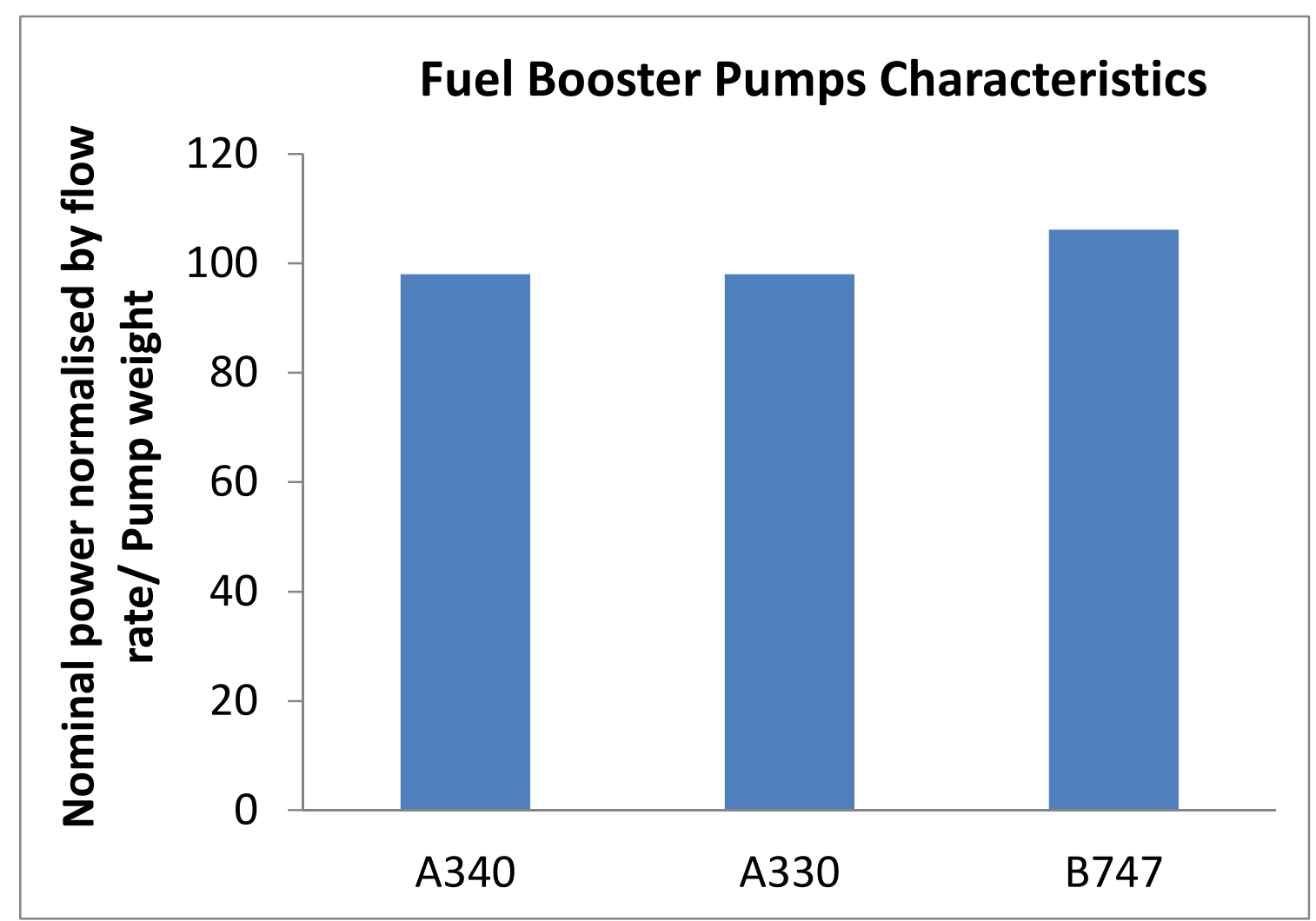

Figure 10: Fuel booster pump characteristics

The Airbus A330 and Airbus A340 uses the same pump while the Boeing 747 has a very similar power to weight ratio once the performance of the pump is normalised by the flow rate to get a similar functionality.

In order to justify that the methodology is appropriate and that the assumption is valid, an uncertainty analysis was conducted. Within the study it was established that 
each electrical component could vary between $85 \%$ and $115 \%$ of the generic nominal power listed in the database.

This type of analysis is needed since, during the development cycle of the aircraft many technologies especially those related to electrical equipment evolve rapidly. So the final electrical components in the aircraft, though functionally similar, may have different power consumption ratings than a previously established baseline. A sensitivity analysis helps determine the effect of variations at the component level to the aircraft level electrical loading. Moreover, the $\pm 15 \%$ can be applied to all components to find the extreme, but this would be a conservative approach that may lead to over-design. So in this study, the approach has been to apply a random change, with $\pm 15 \%$ as the limits, to each component and to perform a thorough sensitivity and un-certainty analysis.

Due to the lack of data, individual distributions for the variation of the nominal power, for a specific component across the large commercial aircraft range, could not be established. So a conservative range for the nominal power was established using results obtained from Figure 7 . Here, it was observed that for a power factor of 0.8 , the IPS total load varied by $15 \%$. This was the basis of the range. This range was based on two assumptions. Firstly it assumed that the Boeing 777-300 had an overall power factor of 0.8 and is the worst case scenario. It was also assumed that each component in the system contributed equally to the variation. This meant that each component in the system on-board the actual aircraft was operating at $85 \%$ of the nominal power to those in the generic database. Hence the range of $\pm 15 \%$ was established. 
Each component was assigned a random power based on the above limit, at each iteration of the process. Figure 11 shows that the range of $\pm 15 \%$ of the nominal value covered all published ratings. It is for the beverage maker on board the aircraft. Similarly every other component power was randomly changed as per a normal distribution.

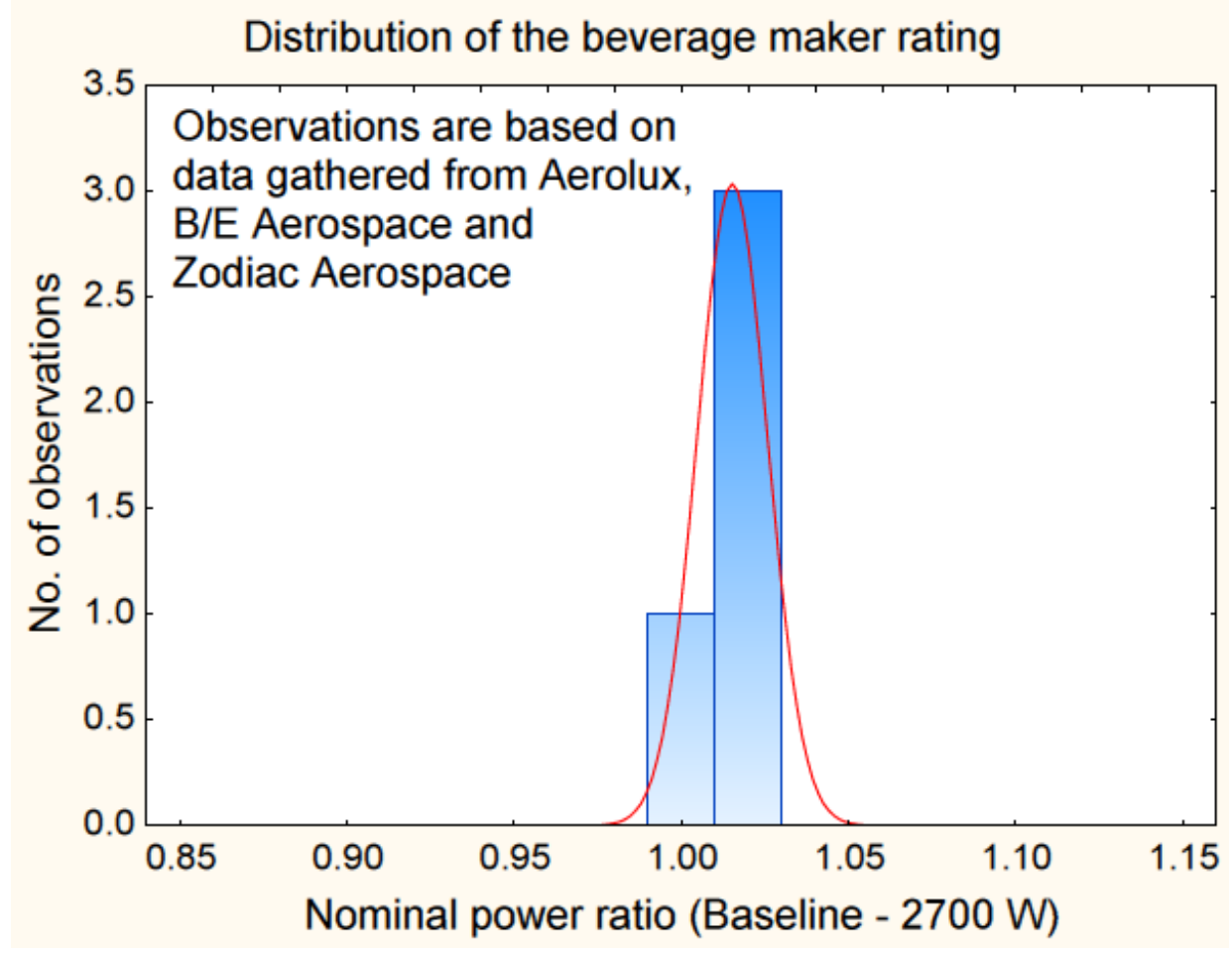

Figure 11: Distribution of the operating power for typical a beverage maker estimated for this research study

Each flight segment was analysed to observe the effect of the uncertainty of the component power. 
Distribution of total electrical load due to component power uncertanities

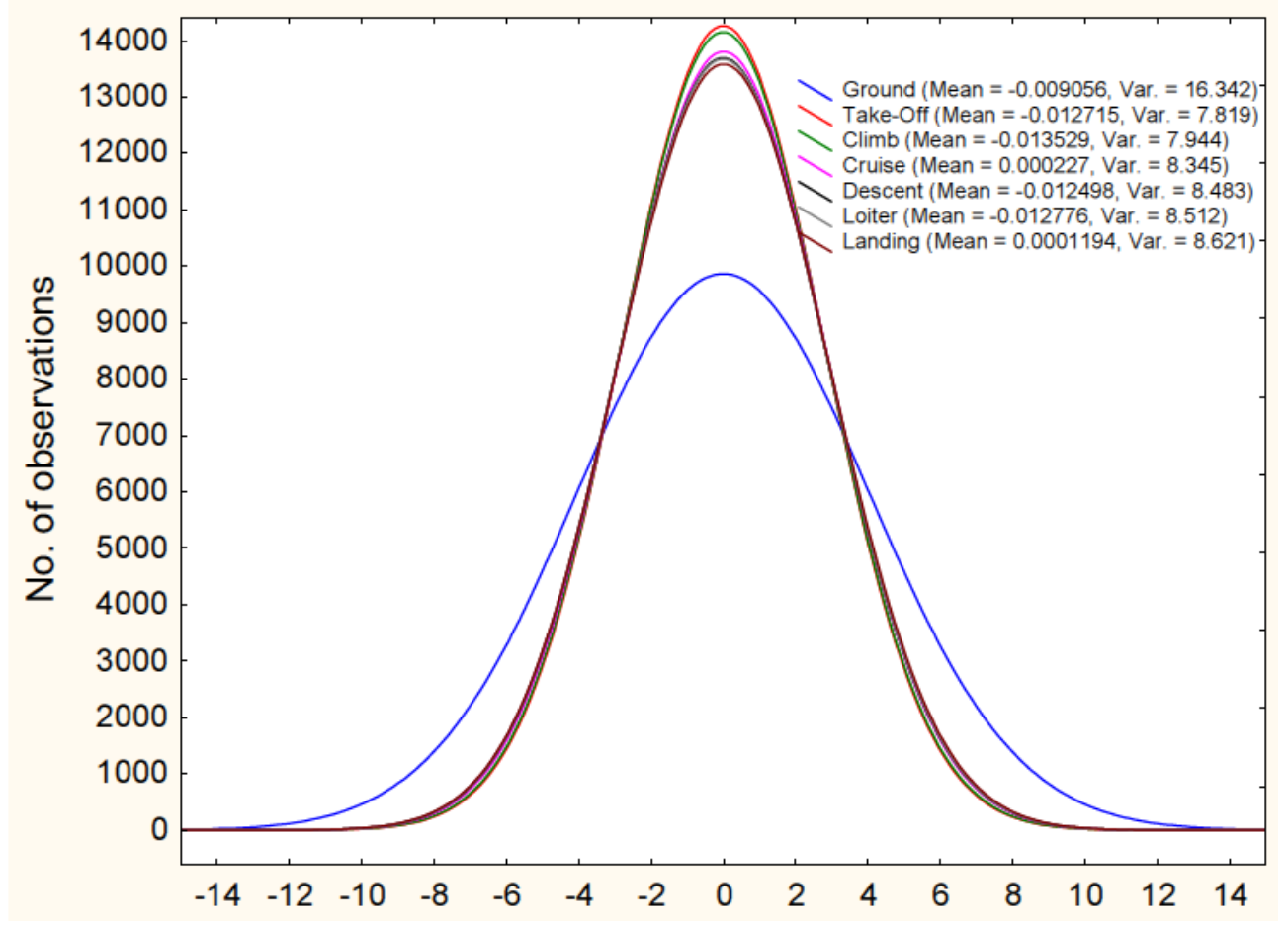

Figure 12: Uncertainty analysis for each flight segment

The following is a summary of the results;

Table 2: Results summary of uncertainty analysis

\begin{tabular}{|c|c|c|c|c|c|c|c|}
\hline \multirow[b]{2}{*}{ Limit range } & \multicolumn{7}{|c|}{ Percentage of cases falling within the limit range } \\
\hline & Ground & $\begin{array}{c}\text { Take- } \\
\text { Off }\end{array}$ & Climb & Cruise & Descent & Loiter & Land \\
\hline Within $2.5 \%$ of baseline & 40 & 62 & 61 & 60 & 58 & 58 & 59 \\
\hline Within $5 \%$ of baseline & 76 & 93 & 92 & 92 & 92 & 92 & 91 \\
\hline Within $7.5 \%$ of baseline & 95 & 99.6 & 99.6 & 99.4 & 99.6 & 99.6 & 99.5 \\
\hline Within $15 \%$ of baseline & 100 & 100 & 100 & 100 & 100 & 100 & 100 \\
\hline
\end{tabular}


The results indicate that nearly all cases fall within $85 \%$ of the baseline case. With the exception of the "Ground" segment, a majority of the cases fall within $99 \%$ of $7.5 \%$ of the baseline calculation. This indicates that the total electrical load change for the aircraft is not affected significantly due to the change in the power for a component. Moreover, the limits of $85 \%$ to $115 \%$ are conservative in the sense that it allowed for a greater deviation than that which would be expected in functionally similar components across the commercial aircraft range. This justifies the use of a generic database to design the electrical system of an aircraft at the preliminary stage. Moreover, it also confirms that relating the components on a functionality basis for each system provides results with far greater accuracy than using conceptual sizing parameters.

This result can be summarised by saying that more than $95 \%$ of the cases simulated with varying degrees of component operating power falls within a $7.5 \%$ deviation of the overall aircraft electrical load calculated using the generic component database and as expected $100 \%$ of the cases fall between a $15 \%$ deviation limit.

The results of the uncertainty analysis shows that this methodology is robust, such that the load for each flight segment is computed independently and that it relies on the operation of components, rather than conceptual design parameters.

Since the methodology relies on the component operation, it makes it robust in adapting to new technology. For example, in the avionics field there is great demand for integrated solutions which perform multiple functions. This results in some conventional avionics equipment being obsolete. Moreover, it also means that the power requirement for such an integrated solution would not be a fixed amount but 
would vary in different flight conditions. By using the operational constraints included in the methodology, the tool can be adapted to incorporate such technology for study, at the preliminary electrical system design stages.

\subsection{Overall validation of work}

As stated by Feiner in [3] the "initial power is estimated by scaling previous designs or by estimating power on a per-passenger basis during the advanced aircraft configuration studies." Moreover, this means that the much of the electrical distribution and generation design can only take place once the other system components are fully defined.

By using generic components as a baseline and by relating the system components to the aircraft level, systems level and operational level requirements, a full electrical load analysis can be achieved in the preliminary design stage. This has a distinct advantage over using conceptual metrics such as the maximum take-off weight and the number of passengers to size/re-size the systems. Moreover, the design of the electrical system can now be done in parallel to the other systems. At the detailed design stage, once the other system components are fully defined, by simply varying the characteristics of the components such as the nominal load the preliminary Electrical Load Analysis (ELA) can be adjusted to provide the final electrical load profile and analysis required for certification. This makes the methodology robust in design as well as post design analysis, giving it the capacity for it to be adapted and modified to different design and operational conditions. 


\section{Results}

One of the primary objectives of this research was to provide a methodology to size the electrical load. The tool developed, will produce electrical load profiles which will enable designers to estimate the capacity of the electrical power sources namely the generators and the Auxiliary Power Unit (APU) by incorporating allowances for distribution and efficiency losses. The default setting of the simulation is a cold night cruise where worst possible conditions are assumed. This follows the certification requirements in which the aircraft should be able to supply the maximum possible electrical load at any given time.

Three case study aircraft were chosen. The case studies were chosen such that both short range and long range aircraft were represented.

1. A long range aircraft with 4 engines, 440 passengers, and a range of 13,700 $\mathrm{km}$.

2. A short range aircraft with 2 engines, 180 passengers and a range of 6,150 $\mathrm{km}$.

3. A long range aircraft with 4 engines, 524 passengers and a range of 13,450 $\mathrm{km}$.

All aircraft are considered to have fly-by-wire technologies. The continuous loading is discussed since this is the primary factor which influences the sizing of the primary electrical generation.

The aircraft level results for each case study are presented and the similarities between the operational aircraft power consumption and the case study aircraft 
power consumptions are discussed. This is followed by a discussion of the tool's ability to calculate the emergency power requirements of a given electrical architecture, as well as the individual bus loading. It should be noted that only the split-bus architecture has been used since it is the typical configuration in most commercial passenger aircraft in operation at present.

The results then present the tools ability to breakdown the power usage in terms of sub-systems within the aircraft secondary power system. Finally, the results show the tool's adaptability to design and analyse a more electric secondary power system.

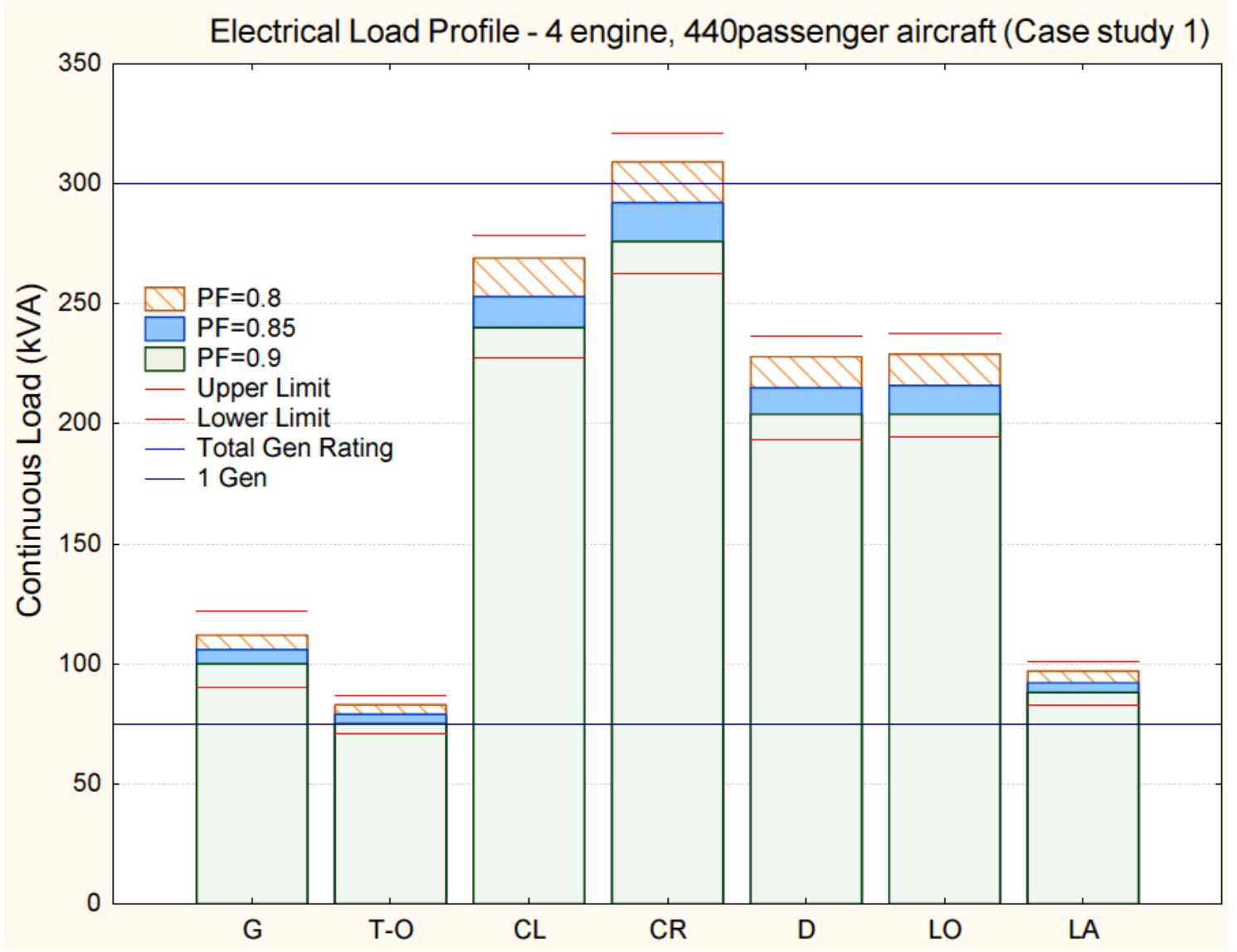

Figure 13: Case study aircraft 1 - ELA 
The characteristics of Case study 1 are similar to that of the Airbus A340-300. The A340 has a total rated capacity of 300 kVA and is shown on the graph for easy comparison(Blue Horizontal lines represent the total and single generator ratings). Case study aircraft 1 requires a maximum of $282 \mathrm{~kW}$. If a power factor of 0.85 is assumed, the maximum load required will be $292 \mathrm{kVA}$. This compares well with the total engine mounted generator rating. But it should be noted that a safety factor needs to be considered to avoid over loading the system. This leads the result to be slightly oversized, but still within a very accurate range for preliminary design.

As can be seen on Figure 14, the power requirements for Case study aircraft 2 with 180 passengers, with a maximum range of $6150 \mathrm{~km}$, with fly by wire technology, and 2 engines is presented.

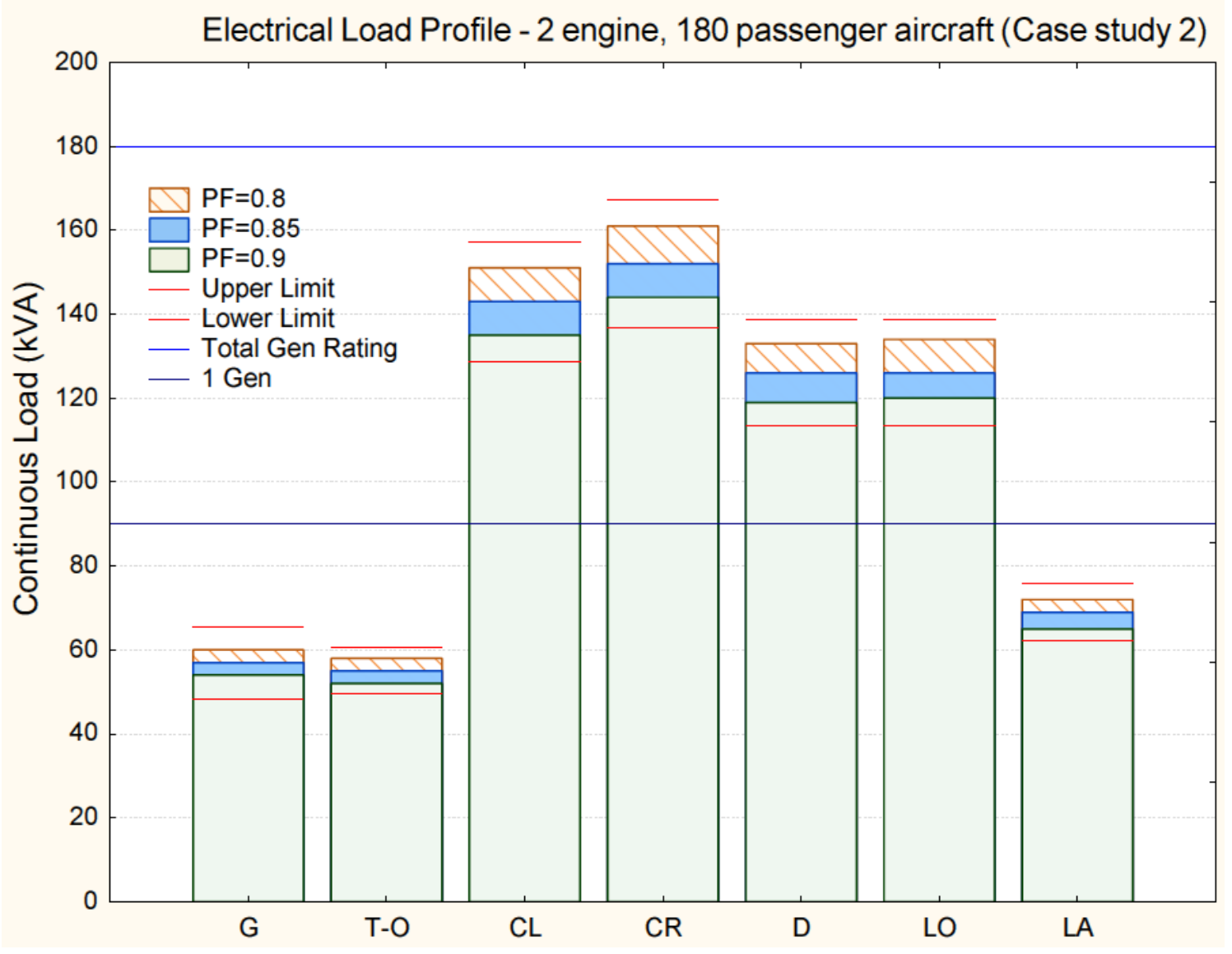


Figure 14: Case study aircraft 2 - ELA

The results show that maximum load required is about $150 \mathrm{~kW}$. This translates into about $161 \mathrm{kVA}$ for a power factor of 0.85 . If the Airbus A320 is considered, the aircraft is a twin engine, 180 passenger aircraft with a maximum range of about 6150 $\mathrm{km}$. It has a total rated capacity of $180 \mathrm{~kW}$. The generator ratings for the A320 are shown on the graph for easy comparison. In this case the model seems to provide a result which is about $11 \%$ less than a comparative aircraft. This is still within an acceptable range at the preliminary design stage.

Case study 3 which is comparative to the Boeing $747-400$ was included in the study, since both previous case study aircraft had Airbus aircraft as comparatives. Moreover, the methodology developed in this research was intended to be as generic as possible. Hence it was expected to perform well regardless of the airframe manufacturers and their bespoke design methodologies. 


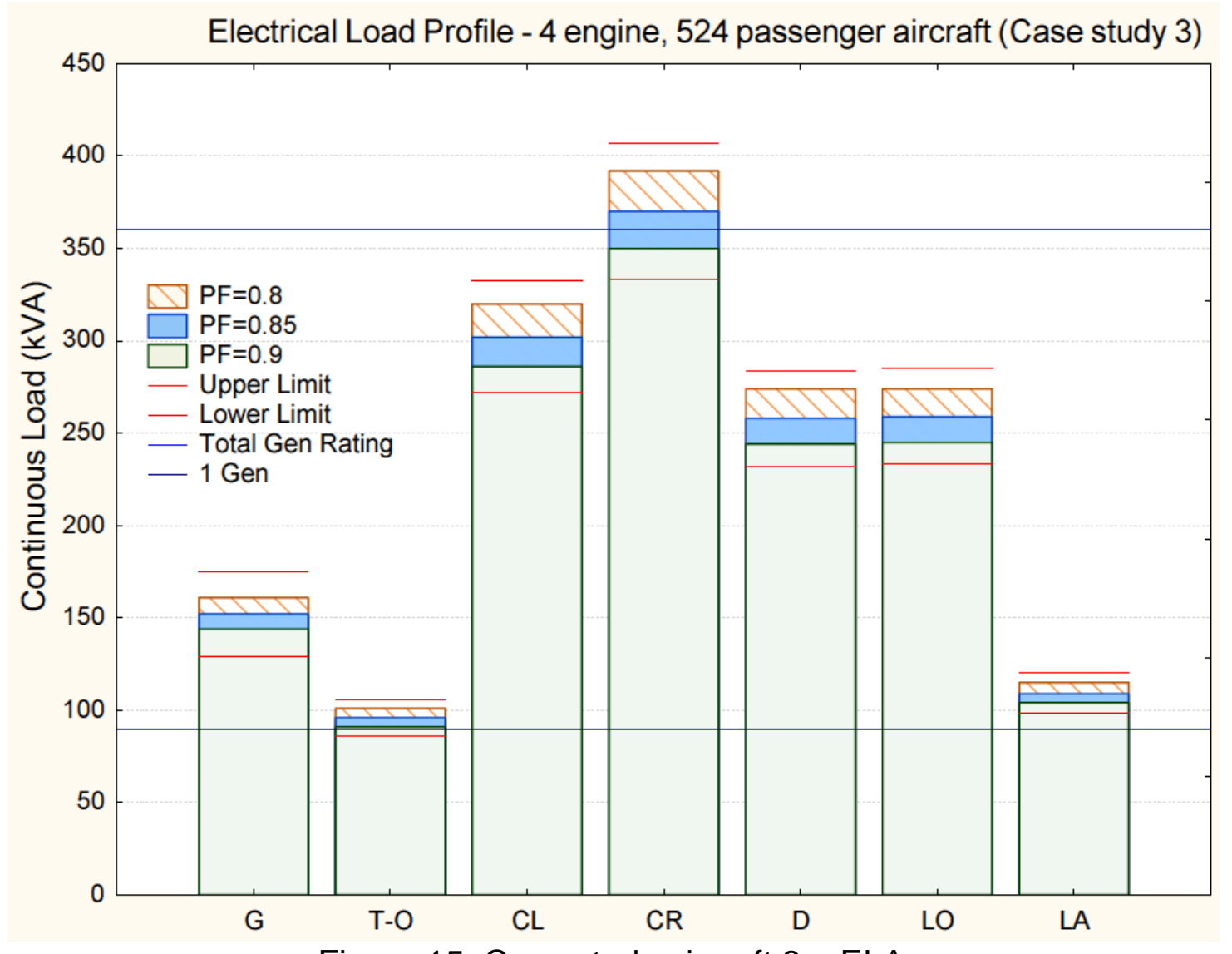

Figure 15: Case study aircraft 3 - ELA

Case study aircraft 3 requires a maximum electrical load of about 338 kVA at a power factor of 0.85 . The Boeing $747-400$ has a total engine mounted generator capacity of $360 \mathrm{kVA}$. The generator ratings for the B747-400 are shown on the graph for easy comparison. Hence the result is well within range of the comparative aircraft.

Each load analysis profile has an upper and lower limit. This is to account for any uncertainty that may be caused due to the uncertainty of the choice of components at the detailed design stage. The limits are a result of the uncertainty analysis discussed previously and make sure the sizing range accounts for more than $99 \%$ of the different configurations possible. 
The assessment of the electrical power required during an emergency is critical to size the ram air turbine and establish the load shedding as well as size the emergency power supply buses. Figure 16 provides results showing the capacity of the essential and vital loads that need to operate during an emergency in Case study aircraft 2. For example these loads will be the loads operating on the essential bus and the shed bus on distribution systems with split bus architectures.

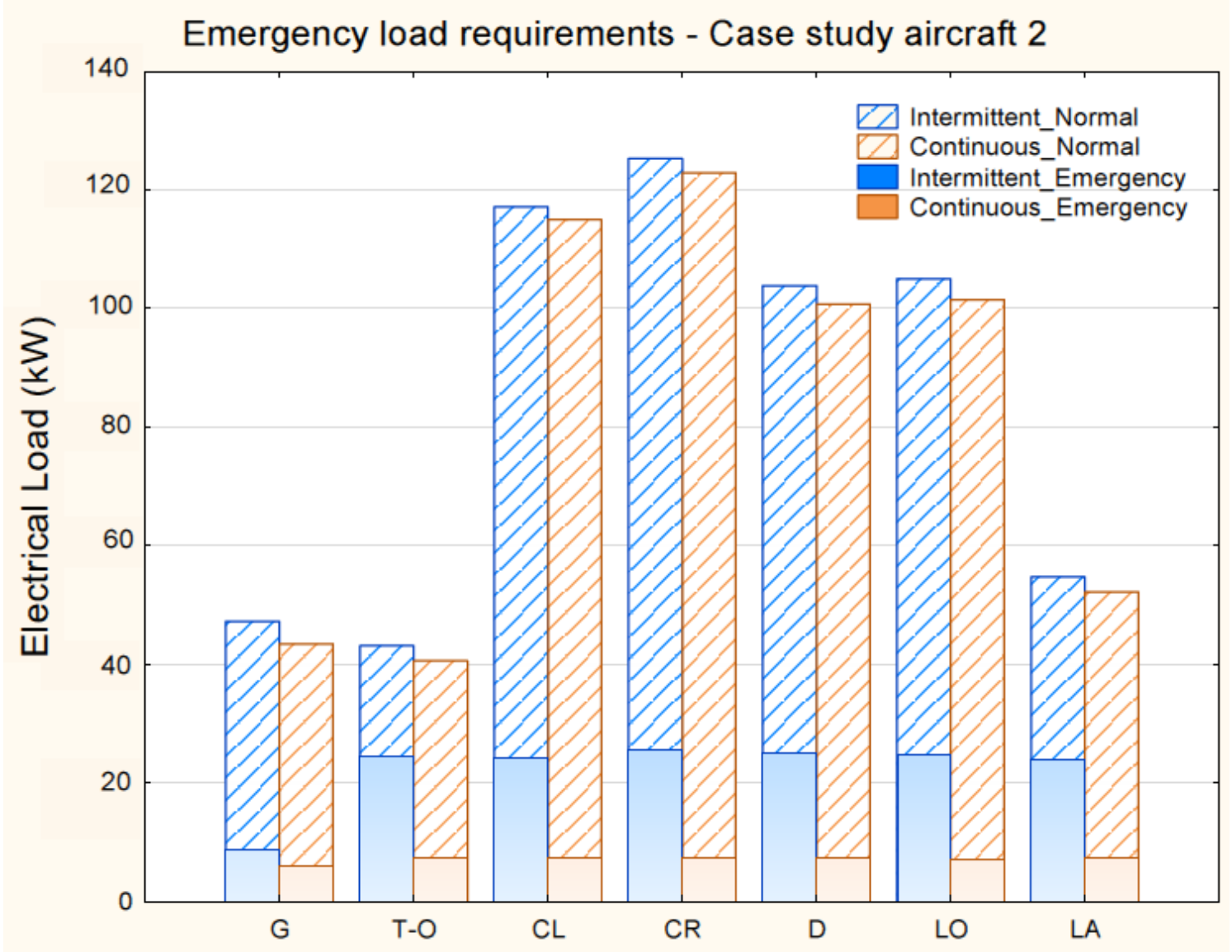

Figure 16: Emergency power analysis for 5 minute duration - Case study aircraft 2 


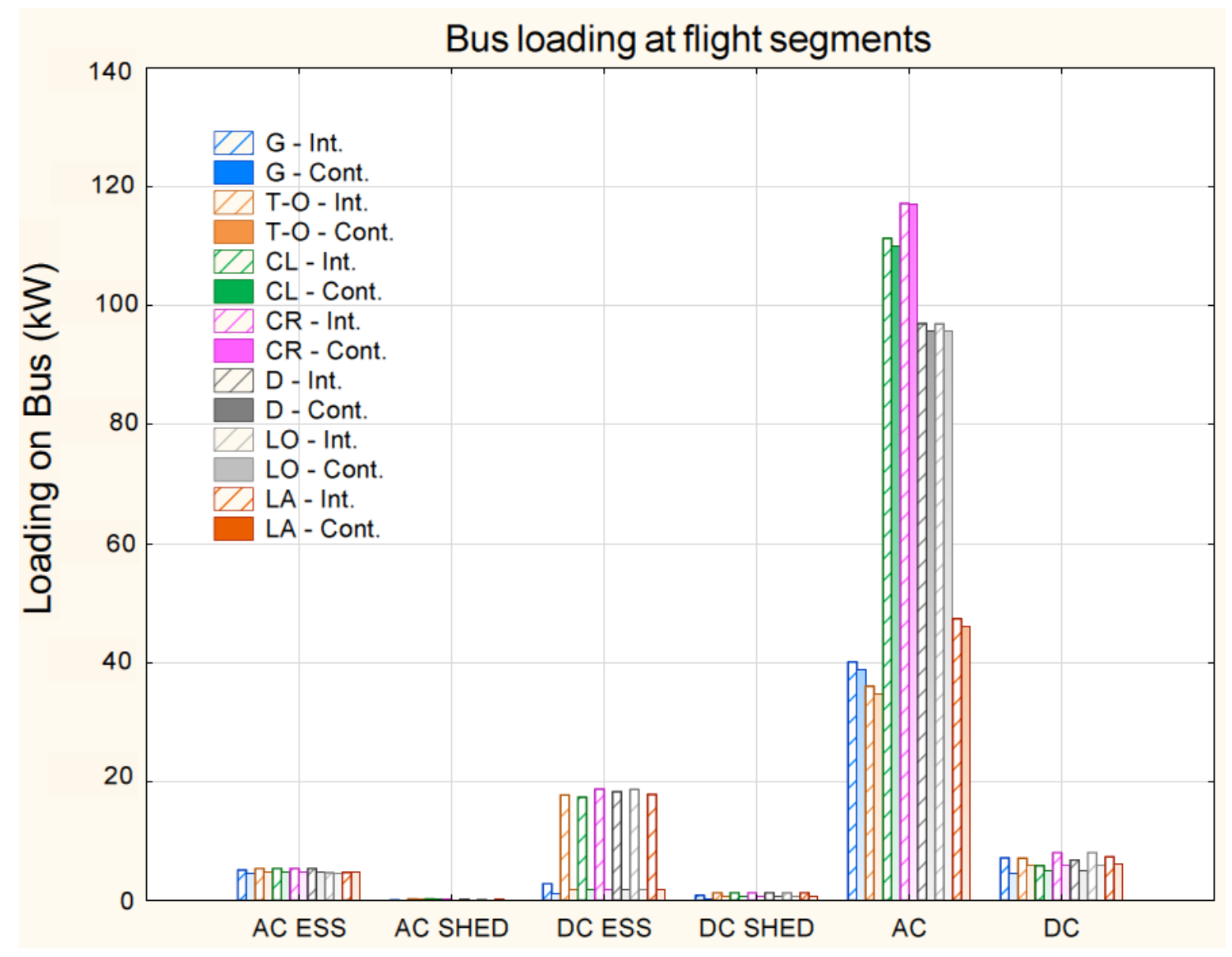

Figure 17: Electrical power requirements as per priority of load - Case study aircraft 2

In order to estimate the sizes of power conversion equipment, emergency power sources, and establish load shedding schedules, details of the operating conditions of each load and its priority needs to be assessed. As discussed previously the tool evaluates and lists loads under six categories as shown in Figure 17 and the analysis provides a method of sizing the buses or load management centres as required by the distribution architecture. 


\section{Systems power requirements during Cruise (W)}

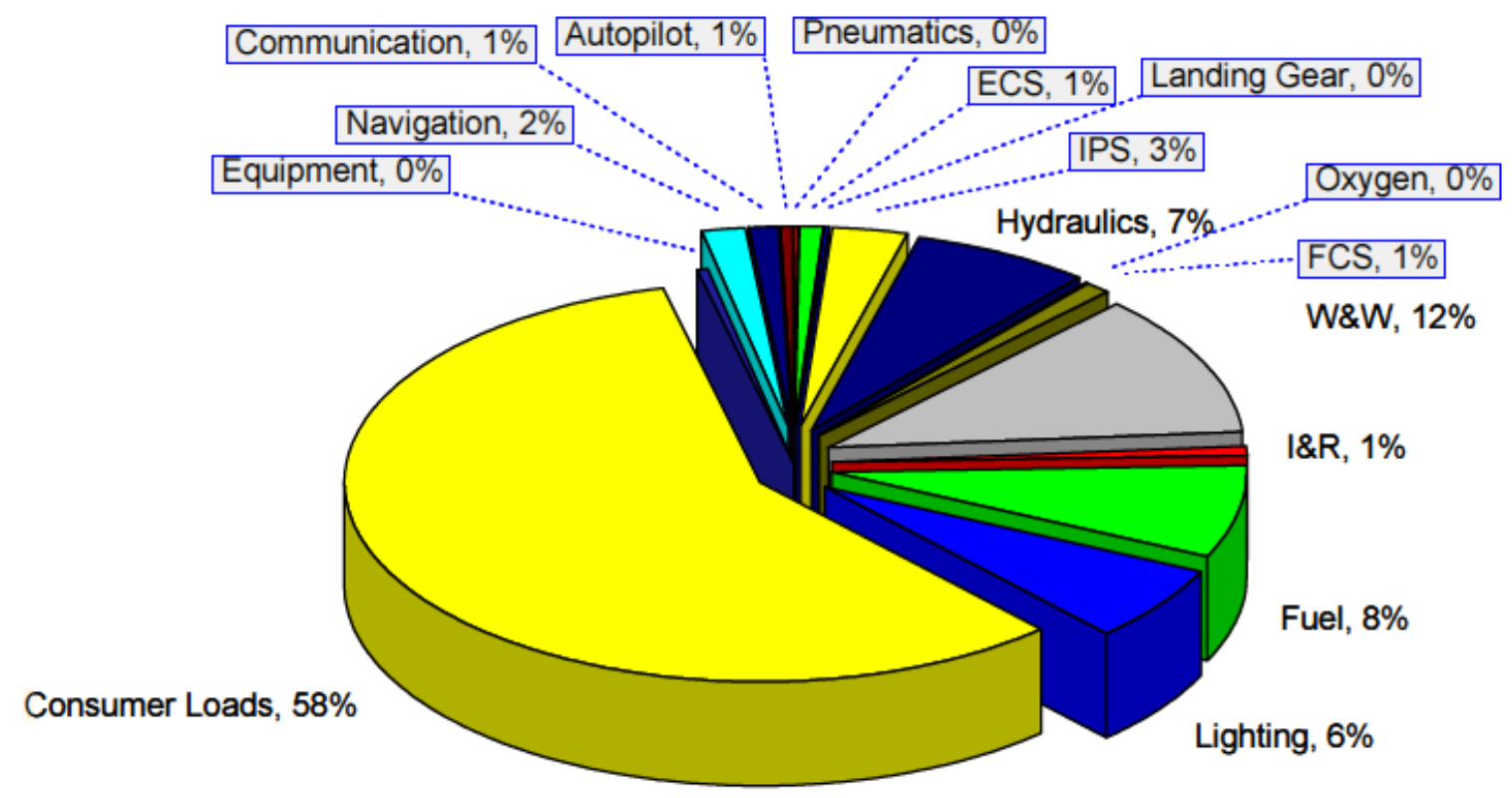

Figure 18: System loads (electrical) during the cruise phase - Case study aircraft 2

Figure 18, shows the breakdown of electrical power usage during the cruise, as per the ATA chapter. As expected ATA 25 which includes the galley and the in-flight entertainment, is the biggest user of electric power while ATA 38 which includes the water heaters and vacuum generators for the lavatories consume $12 \%$ of the electric consumption which makes it the second largest consumer of electric power.

The sensitivity analysis performed by the tool is also important to assess the impact of a component at the aircraft level power consumption. This provides the basis to judge the sizing or re-sizing of the electrical sources without repeating a further electrical load analysis which increases the efficiency and the robustness of the design procedure itself.

Once the baseline aircraft and the baseline architecture of the systems is established within the tool, mathematical functions can be formulated to represent the electrical 
power requirement of each airframe system so that further design analysis can be conducted on variants which have similar systems architectures.

The following is the correlation for the pneumatics and ECS electrical power consumption for Case study 2. The ECS in this test case provides pressurization, temperature regulation and ventilation. The pneumatics provides the bleed air required to run the ECS and IPS. The results from the system level analysis can be summarised by factorising and grouping parameters related to sub-functions of the system. Since certain equipment have multiple functionalities, this grouping of terms can be done in many ways and the following is just one example.

$$
\begin{aligned}
P_{E C S}+\text { Pneu }= & 30\left(N_{P C}+N_{Z C}+8 N_{B F}\right)+17\left(N_{A P U}+1\right)+4\left(31 N_{C P}+48 N_{A C}-8\right)+ \\
& {\left[14\left(N_{R A M}+10 N_{E}+6 N_{R F}\right)-N_{E}+8 N_{R F}\right]+152 N_{C C} }
\end{aligned}
$$

$N_{P C}$ - number of pressure controllers

$N_{z C}$ - number of zone controllers

$N_{B F}$ - number of blowers in the avionics compartments

$N_{A P U}$ - number of APU

$N_{C P}$ - number of conditioning packs in the ECS

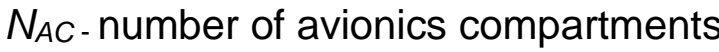

$N_{R A M}$ - number of ram air inlets

$N_{E}$ - number of engines

$N_{R F}$ - number of re-circulation fans

$N_{C C}$ - number of cabin compartments

A numerical relationship for each sub-system power requirement can be formed as above. This is achieved by relating aircraft level and system level parameters to the 
minimum equipment needed to achieve the functionality of a given sub-system, and a generic data set containing typical power consumption values for each electrical component in the sub-system.

To calculate the power usage at different flight stages, co-efficients can be used to multiply $P_{E C S+P n e u}$. At ground (which is defined as prior to engine start up and passenger boarding) the co-efficient for the 5 minute load is calculated as 0.0105 and 0 for the 15 minute load. For all other flight phases the 5 minute load co-efficient will be 1 and the 15 minute load co-efficient will be 0.8623 .

This process can be done for all systems to simplify the relationship between the functions, components, power usage and operations (as per flight phases). This information can then be used to re-size the systems themselves or design and adapt systems for aircraft families.

\section{Adaptability and implementation in a MEA design}

This model was adapted and implemented for a design of a more electric aircraft electrical system. Since all systems now run on electricity, the electrical load analysis included additional loads. These loads represented the pneumatic and hydraulic loads in the conventional aircraft which will be substituted by electrical components.

The significant loads were the electrical environmental control system compressor which draws in ram air, the electrical heating devices/mats for the electric wing and tail anti-icing / de-icing systems and the electrically powered actuators. 
Moreover, the electrical components such as bleed computers in the pneumatics and leak measurement valves in the hydraulic system in the conventional configuration were made redundant.

To test the adaptability of the tool, case study 2 was converted into a MEA. The summary of the loads are shown below;

From [23] a benchmark for an electrical ECS power demand was derived. It suggests that for a typical hot day cruise at $40,000 \mathrm{ft}$, a typical electrical ECS will consume about $1.17 \mathrm{~kW} /$ per passenger for ventilation, pressurisation and cooling of the cabin. An in-house developed electrical ECS simulation tool was tested at similar conditions for the "case study 2" aircraft. The ISA deviation to represent the hot day was calculated using [24]. The electrical power for the compressor was based on (6), (7) and (8);

$$
\begin{gathered}
P_{\text {net_EECS }}=W^{\prime} U A T_{C} \\
W^{\prime}=m T_{e}^{\prime}\left[P_{e}^{b}-1+\frac{\varepsilon}{\varphi}(\varphi-1)\left(\varphi-P_{e}^{b}\right)\right] \\
b=\left(\frac{\gamma-1}{\gamma}\right)
\end{gathered}
$$

Where,

$P_{\text {net_EECS }}$ - net power for the electric ECS

$U$ - thermal conductivity of the cabin skin

$A$ - wall area of the cabin

$T_{c}$ - cabin temperature

$m$ - mass flow rate of air 
$T^{\prime}{ }_{e}$ - ratio between the ambient and cabin temperatures

$P_{e}-$ ratio between the ambient and cabin pressures

$\mathcal{\varepsilon}$ - efficiency of the heat exchanger

$\varphi$ - ratio between the ambient and the aft compressor temperatures

$y$ - ratio of specific heat of air

This model calculated a ratio of $1.21 \mathrm{~kW} /$ per passenger for case study 2 during a hot day cruise flight at $40,000 \mathrm{ft}$. It was a deviation of $3.8 \%$ thus the model was accurate to be used in further analysis. The avionics cooling load which is relatively low compared to the cooling of the cabin was not accounted for, since the equations presented above are for a simplified electrical ECS.

The maximum power for the wing ice protection was interpolated using Figure 3 and Figure 4 as $136.8 \mathrm{~kW}$.

Due to the availability of data the maximum loads for the actuators were scaled as a first iteration using the maximum number of passengers as a sizing factor from Figure 3. It should be noted that detailed actuator models would provide more accurate power predictions, and that a first approximation is used to demonstrate that the tool developed in the research is capable of being adapted to MEA electrical load analysis.A summary of the actuator loads is shown below;

- Slats

- Horizontal stabilizer

- Spoilers

- Flaps

- Rudder

$\begin{array}{ll}- & 19 \mathrm{~kW} \\ - & 23 \mathrm{~kW} \\ - & 44 \mathrm{~kW} \\ - & 7 \mathrm{~kW} \\ - & 11 \mathrm{~kW}\end{array}$


- Elevator

- Ailerons

- Landing gears
$-$

$-$

$-$
$28 \mathrm{~kW}$

$39 \mathrm{~kW}$

$29 \mathrm{~kW}$

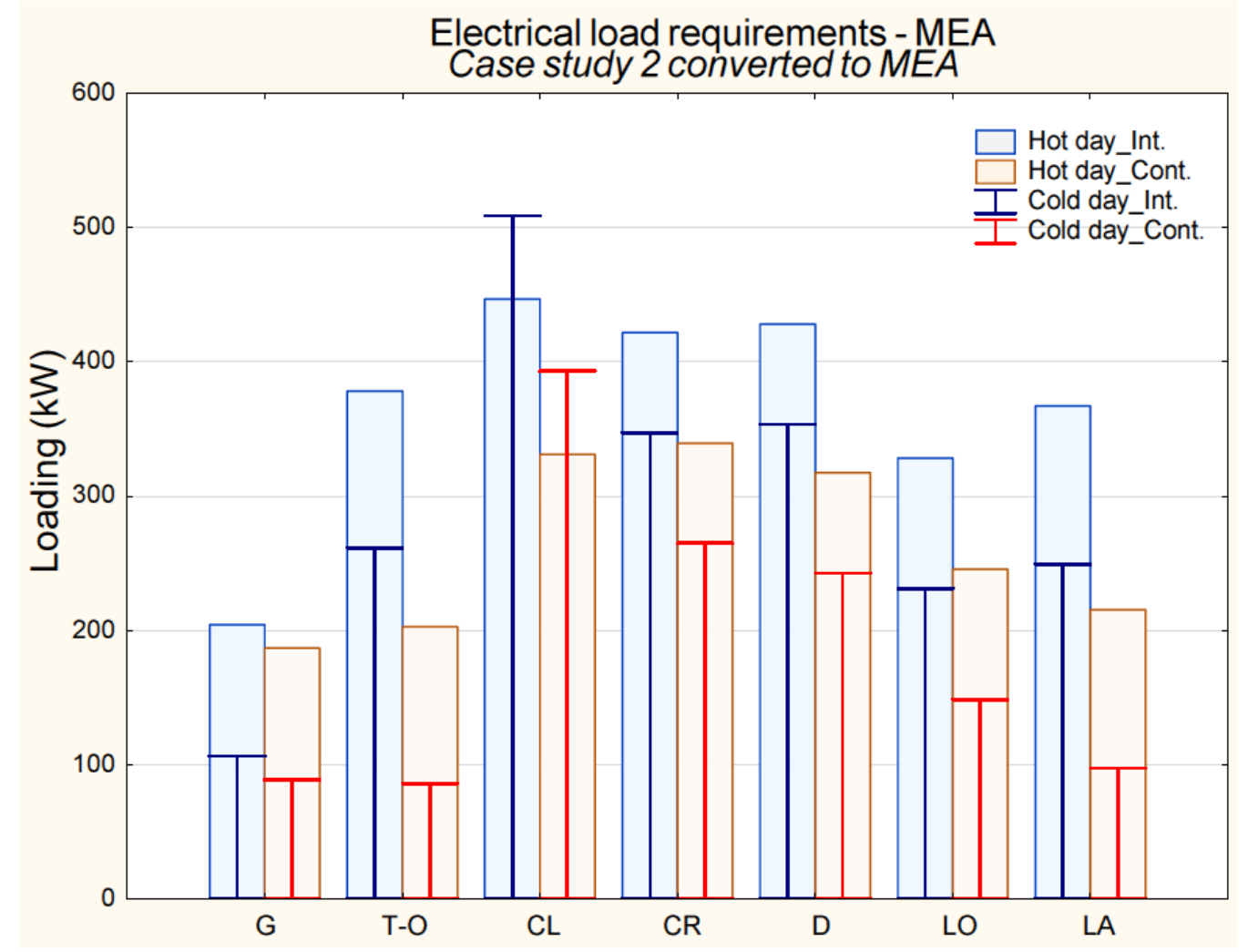

Figure 19: Electrical loading for more electric case study 2 aircraft

Figure 19 gives a top level indication as to what challenges MEA design will face. The obvious challenge is the significantly higher electrical load demands that must be satisfied by the electrical generation."Int." refers to intermittent loads and "Cont." refers to continuous loads.

Moreover, it also presented a challenge in choosing the design case. For example by simulating the electrical ECS it is clear that the design case is a hot day cruise. Yet if this condition is selected for the overall aircraft loading study, the loads from the IPS may not be represented. On the other hand, if a cold night cruise is selected, then 
the risk of icing is very high, hence the IPS loads will be at a maximum. But the maximum possible loads for the ECS will not be represented, thus if sized for this condition, it will not be adequate to run the electrical ECS. Hence intelligent power management solutions will be required to satisfy both scenarios and avoid oversizing of the electrical system.

Figure 19 shows that the sizing case, in this instance is the climb segment during a cold night cruise. Yet in all other segments, the hot day cruise requirements are greater.

Moreover, the illustration below shows that the electric ECS accounts for about $52 \%$ of the total electrical load during a hot day cruise. The cruise altitude is $35,000 \mathrm{ft}$ and the cruise Mach number is 0.8 .

\section{Intermittent load distribution at Cruise}

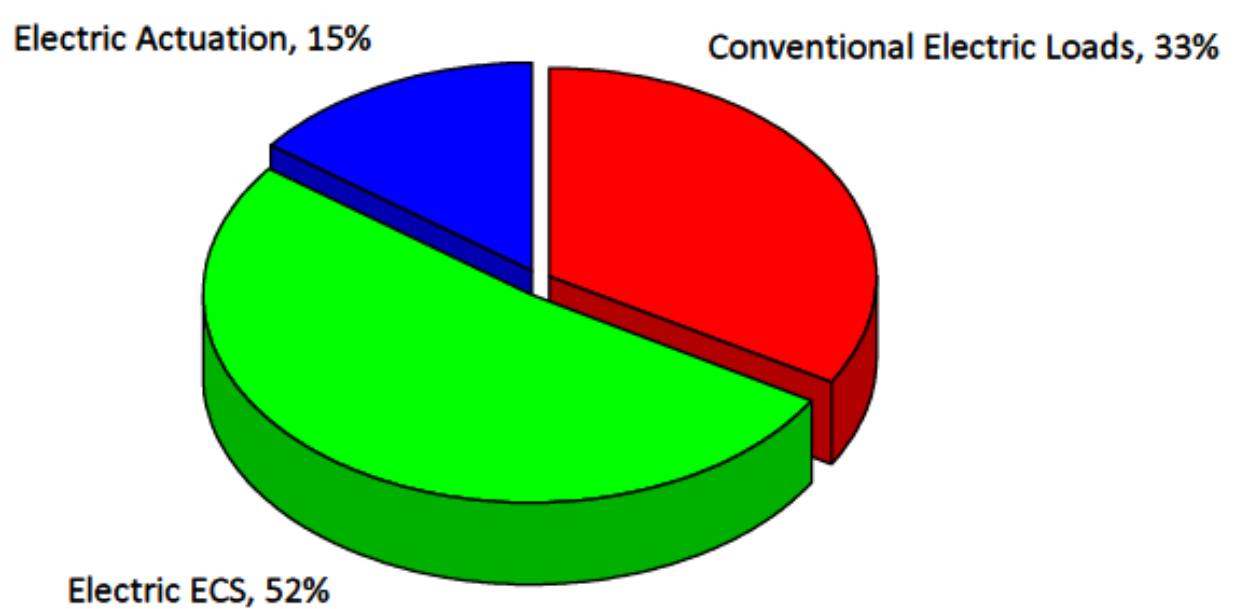

Figure 20: Distribution of loads at cruise in the MEA case study 2 


\section{Conclusion and future work}

The tool discussed within this paper has been developed to size the electrical loads of an aircraft (at the preliminary design stage) with relation to aircraft level, system level and operational level inputs and constraints. As part of the validation procedure, a sensitivity analysis has been incorporated in to the tool itself, thereby showing the user the impact of an over-rating or under-rating of a component compared to the baseline calculation using the generic component database. The methodology was successfully validated at component, system and aircraft level.

The methodology can be applied to any aircraft thus providing a means of sizing the electrical load at the preliminary design phase. The tool can also be adapted to incorporate additional components to satisfy future aircraft systems. The robustness and efficiency of the design process can be increased by using the sensitivity analysis which is in-built in the tool.

In converting case study 2 into a more electric aircraft, it was observed that the conventional electric load is only $33 \%$ of the total load. This re-establishes the significance of the electrical sizing, design and analysis at the preliminary design stage of the aircraft. Moreover, this methodology and the consequently developed sizing tool provides a solution to improve the design of the aircraft electrical system at the early stages of the design process.

The sizing tool discussed in this paper can be further improved by integrating detailed models for electrical ECS, electro-thermal IPS, EHA systems and EMA systems. An example of the adaptability was presented using estimations and $1^{\text {st }}$ iterations systems models for the electrical ECS, IPS and actuators. This will give the 
user the ability to simulate the electrical system of a conventional aircraft or a more electric aircraft. Moreover, the output from this study can be used to size and analyse the electrical distribution system such as that described in [25] at a very early design stage thereby reducing the risk of the design as well as making the design process much more efficient. It will also give indications as to the preliminary requirements for power management and scheduling requirements.

The purpose of the sizing tool is to aid design of the aircraft. The operation of the aircraft is also a key aspect in making the aircraft an efficient system. The sizing tool can be coupled with an operational constraints model, which includes models for pilot behaviour and passenger behaviour, to simulate the electrical power requirement during operation of the aircraft thereby aiding the design of effective energy management and load scheduling systems at the preliminary design stages. 


\section{References}

1. ICAO - Chief Economic Analysis \& Policy Section. AVIATION STATISTICS \& DATA: A VITAL TOOL FOR THE DECISION MAKING PROCESS. 2011..

2. Arguelles $P$, Bischoff $M$, Busquin $P$, Droste $B$, Evans $R$, Kroll $W$, et al. EUROPEAN AERONAUTICS: A VISION FOR 2020 - Meeting society's needs and winning global leadership. Luxembourg:; 2001.

3. Feiner LJ. POWER-BY-WIRE AIRCRAFT SECONDARY POWER SYSTEMS. In Digital Avionics Systems Conference; 1993: AIAA/IEEE.

4. Roskam J. Airplane Design: Roskam Aviation and Engineering Corporation; 1989.

5. Raymer DP. Aircraft Design: A Conceptual Approach. Fourth Edition ed.: AIAA; 2006.

6. Howe D. Aircraft Conceptual Design Synthesis: Professional Engineering Publishing Limited; 2005.

7. Kundu AK. Aircraft Design: Cambridge University Press; 2010.

8. Airbus. Airbus A300 Engineering Notes Edition 2 Volume 2: Airbus; 1975.

9. Lockheed - California Company. Engineering Description Series - Volume 7, Electrical, L-1011 TriStar: Lockeed - California Company; 1970.

10. CAA - Safety Regulation Group. CAA. [Online]; 2004 [cited 2012 July 05. Available from: http://www.caa.co.uk/docs/33/AlL0194.PDF.

11. Seresinhe R, Lawson C. The MEA Evolution in Commercial Aircraft and the Consequences for Initial Aircraft Design. 2013; 3.

12. Moir I, Seabridge A. Aircraft Systems: Mechanical, electrical and avionics subsystem integration. Third Edition ed.: John Wiley \& Sons; 2008.

13. Renz DD. COMPARISON OF ALL-ELECTRIC SECONDARY POWER SYSTEMS FOR CIVIL TRANSPORT. ; 1992.

14. de Tenorio C, Marvis D, Garcia E, Armstrong M. METHODOLOGY FOR 
AIRCRAFT SYSTEM ARCHITECTURE SIZING. In ; 2008: ICAS 2008.

15. Seresinhe R, Lawson C, Sabatini R. Environmental Impact Assessment, on the Operation of Conventional and More Electric Large Commercial Aircraft. SAE International Journal of Aerospace. 2013 September; 6(1).

16. Esdras GF, Liscouet-Hanke S. An Electrical Load Estimation Tool for Aircraft Conceptual Design. In SAE AeroTech Proceedings, 2013; 2013; Montreal, Canada: SAE International.

17. Kayton M, Fried RW. Avionics Navigation Systems. Second Edition ed.: John Wiley \& Sons, Inc; 1997.

18. Kendal B. Manual of Avionics. Third Edition ed.: Blackwell Scientific Publications; 1993.

19. Tooley M, Wyatt D. AIRCRAFT ELECTRICAL AND ELECTRONIC SYSTEMS PRINCIPLES, MAINTENANCE AND OPERATION: Elsevier Ltd.; 2009.

20. Andrade L, Tenning C. Design of Boeing 777 electric system. 1992; 7(7).

21. Eaton Aerospace Limited. Fuel Boost Pump Type 8810 and Canister Type 8811. Data Sheet. ; 2013. Report No.: 568-1-28300, 568-1-28301.

22. Eaton Aerospace Limited. Fuel Boost Pump Type 20004 and Canister Type 20005. ; 2013. Report No.: 568-1-30685, 568-1-30690.

23. Herzog J. ELECTRIFICATION OF THE ENVIRONMENTAL CONTROL SYSTEM. In ; 2006: ICAS 2006.

24. Walsh PP, Fletcher P. Gas Turbine Performance. Second Edition ed. Oxford: Blackwell; 1998.

25. Xia X, Lawson C. The development of a design methodoloy for dynamic power distribution management on a civil transport all electric aircraft. 2013; 25(1). 
Appendix A - List of inputs for the A300 case study

\begin{tabular}{|c|c|}
\hline \multicolumn{2}{|c|}{ AIRCRAFT LEVEL INPUTS } \\
\hline No. of engines & 2 \\
\hline No. of APU & 1 \\
\hline No. of wings & 2 \\
\hline No. of pilots & 2 \\
\hline APU capacity (kVA) & 90 \\
\hline No. of RAT & 1 \\
\hline No. of passengers (maximum density) & 269 \\
\hline No. of passengers (aircraft variant) & 269 \\
\hline Maximum range(km) & 7500 \\
\hline No. of lavatories & 4 \\
\hline No. of galleys & 6 \\
\hline No. of exits & 8 \\
\hline Cabin volume (m3) & 289 \\
\hline \multicolumn{2}{|c|}{ SYSTEM LEVEL INPUTS } \\
\hline \multicolumn{2}{|l|}{ ECS - ATA 21} \\
\hline No. of conditioning packs & 2 \\
\hline No. of cabin compartments (incl. cockpit) & 3 \\
\hline No. of avionics compartments & 1 \\
\hline No. of cargo compartments & 2 \\
\hline No. of ram air inlets & 1 \\
\hline No. of re-circulation fans in cabin & 2 \\
\hline No. of zone controllers & 1 \\
\hline
\end{tabular}




\begin{tabular}{|c|c|c|c|c|c|c|c|}
\hline \multicolumn{6}{|c|}{ No. of blowers for avionics ventilation } & & \\
\hline \multicolumn{6}{|c|}{ No. of cabin pressure controllers } & & 3 \\
\hline \multicolumn{8}{|c|}{ Landing Gear - ATA 32} \\
\hline \multicolumn{6}{|c|}{ No. of wheels with fans } & & 0 \\
\hline \multicolumn{6}{|c|}{ No. of brake pressure indicators } & & 1 \\
\hline \multicolumn{8}{|c|}{ IPS - ATA 30} \\
\hline \multicolumn{6}{|c|}{ No. of heated windows } & & 2 \\
\hline \multicolumn{6}{|c|}{ No. of heated drain masts } & & 0 \\
\hline \multicolumn{8}{|c|}{ Maintenance - ATA 45} \\
\hline \multicolumn{6}{|c|}{ No. of maintenance computers } & & 1 \\
\hline \multicolumn{6}{|c|}{ No. of displays for maintenance } & & 1 \\
\hline \multicolumn{8}{|c|}{ Hydraulics - ATA 29} \\
\hline \multicolumn{6}{|c|}{ No. of hydraulic pumps per engine } & & 1 \\
\hline \multicolumn{6}{|c|}{ No. of hydraulic systems } & & 3 \\
\hline \multicolumn{6}{|c|}{ No. of HSMU } & & 0 \\
\hline \multicolumn{6}{|c|}{ No. of electric pumps in hydraulic systems } & & 2 \\
\hline \multicolumn{8}{|c|}{ Fuel - ATA 28} \\
\hline \multicolumn{6}{|c|}{ No. of transfer valves to outer tanks } & & 2 \\
\hline \multicolumn{8}{|c|}{ Fuel functionality matrix } \\
\hline & Tanks & Refuel & Jettison & $\begin{array}{l}\text { Trim } \\
\text { transfer }\end{array}$ & $\begin{array}{l}\text { Gravity XFR } \\
\text { to feed tank }\end{array}$ & $\begin{array}{l}\text { Pump XFR } \\
\text { to feed tank }\end{array}$ & $\begin{array}{l}\text { Engine } \\
\text { Feed }\end{array}$ \\
\hline Outer & 2 & $y$ & $n$ & $\mathrm{n}$ & $y$ & $\mathrm{n}$ & $\mathrm{n}$ \\
\hline Inner & 2 & $n$ & $n$ & $\mathrm{n}$ & $n$ & $\mathrm{n}$ & $y$ \\
\hline Centre & 1 & $y$ & $\mathrm{n}$ & $\mathrm{n}$ & $\mathrm{n}$ & $y$ & $y$ \\
\hline
\end{tabular}




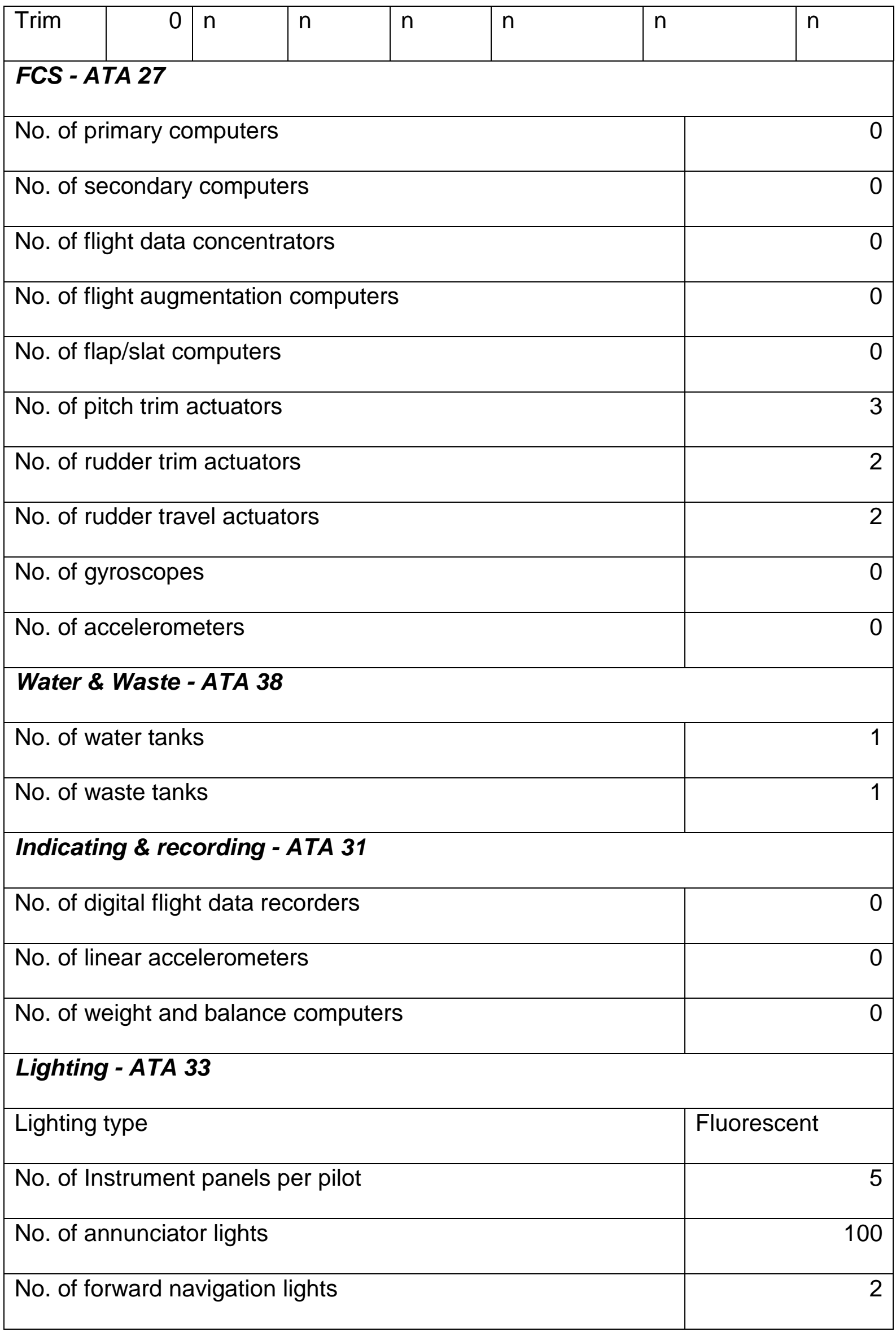




\begin{tabular}{|l|r|}
\hline No. of rear navigation lights & 1 \\
\hline No. of beacon lights & 2 \\
\hline No. of landing lights & 2 \\
\hline No. of runway turn-off lights & 2 \\
\hline No. of taxi and take-off lights & 2 \\
\hline No. of logo lights & 2 \\
\hline No. of wing inspection lights & $\mathrm{n}$ \\
\hline Consumer Loads & $\mathrm{n}$ \\
\hline Do passengers have an in-seat power supply & 1 \\
\hline Do passengers have in-flight entertainment & 1 \\
\hline Are the above two systems integrated & \\
\hline Food heating cycles per serving & 0 \\
\hline Navigation - ATA34 & \\
\hline No. of TCAS & \\
\hline No. of PVI & \\
\hline No. of AHRS & \\
\hline Autopilot - ATA 22 & \\
\hline No. of flight management guidance computers & 0 \\
\hline No. of FMS display units & \\
\hline No. of flight control units & \\
\hline No. of FMS data loaders & \\
\hline No. of rudder trim actuators used at a time & \\
\hline
\end{tabular}




\begin{tabular}{|l|r|}
\hline No. of rudder travel actuators used at a time & 1 \\
\hline Fraction of annunciator lights on ground & 0.2 \\
\hline Maximum fraction of simultaneous galley operation & 1 \\
\hline
\end{tabular}


2014-05-13

\section{Electrical load-sizing methodology to aid conceptual and preliminary design of large commercial aircraft}

Seresinhe, Ravinka

Sage

Seresinhe R \& Lawson C (2014) Electrical load-sizing methodology to aid conceptual and preliminary design of large commercial aircraft, Proceedings of the Institution of Mechanical Engineers, Part G: Journal of Aerospace Engineering, 229 (3) 445-466.

https://doi.org/10.1177/0954410014534638

Downloaded from Cranfield Library Services E-Repository 